\title{
NUEVAS ESPECIES AMERICANAS DE TURNERA (TURNERACEAE)
}

\author{
por MARIA MERCEDES ARBO
}

\begin{abstract}
Summary
The survey of herbarium material for the revision of the genus Turnera, and the collection trips made in Brazil in the last three years have allowed the discovery of some new species, described here: $T$. aromatica, $T$. candida, $T$. cipoensis, $T$. gardneriana, $T$. joelii, $T$. prancei, $T$. purpurascens, $T$. rubrobracteata y $T$. urbanii. One new combination: $T$. arenaria (Urban) Arbo, is proposed.
\end{abstract}

\section{Introducción}

El estudio del material de herbario para la revisión del género Turnera, y los viajes de colección realizados a Brasil en los últimos tres años, han permitido detectar algunas especies nuevas, que se describen aquí. Se propone además una nueva combinación.

\section{Turnera aromatica Arbo nov. sp.}

Fig. 1

Frutex 0,5-2,4 m altus, folia 4-15 mm longe petiolata, ovata vel elliptica, 2-10 $\mathrm{cm}$ longa, subtus juxta marginem nectariis discoideis praedita, utrinque tomentosa, subtus pilis capitatis flavis secernentibus brevissime stipitatis intermixtis, venis lateralibus sub angulo $35-48^{\circ}$ abeuntibus; flores axillares, heterostyli, pedunculo 1 $3 \mathrm{~mm}$ longo; calyx 7-15 mm longus, corolla flava; semina 1,6-2,3 mm longa, elevatim longitrorsum \& obsoletius transversim striata.

Facultad de Ciencias Agrarias, UNNE. Miembro de la Carrera del Investigador Científico, CONICET. Instituto de Botánica del Nordeste, C.C. 209, 3400 Corrientes, Argentina. 
Typus: Belize, Orange Walk District, between London and Carmelita along the old Northern Highway between Orange Walk and Maskall, 88 $28^{\prime}$ W $17^{\circ} 59^{\prime} \mathrm{N}$, elev. $50 \mathrm{~m}$, Eleocharis marsh surrounded by Acoelorraphe palm and brushy savanna, brushy margin of marsh, shrub 1.5 m, flowers yellow, 20.III.1987, Davidse G. \& A.E. Brant 32816 (holotipo, CTES; isotipo, MO).

Arbusto 0,5-2,4 $\mathrm{m}$ alt., ramas viejas con corteza pardo-rojiza, longitudinalmente estriada, con lenticelas pequeñas más o menos circulares, cicatrices foliares salientes; ramas del año 1-5 mm diám., con pelos cortos, crespos y pelos largos antrorsos, generalmente con entrenudos cortos, las ramas de brotes vigorosos con entrenudos largos. Yemas axilares seriales 1-4, generalmente con desarrollo acrópeto, la basal florífera, ramas seriales frecuentemente desarrolladas. Hojas discoloras, frecuentemente agrupadas en los extremos de las ramas. Estípulas triangulares, pilosas, 0,3-0,7 mm long., persistentes poco después de la caída de las hojas. Pecíolo semicilíndrico, 4-15 mm long., indumento como en el tallo o más denso. Nectarios 2-4, discoideos, brevemente estipitados, 0,3-0,8 mm diám., ubicados en la unión de pecíolo y lámina o distantes 1-5 mm de la base, sin reborde, poro no visible. Lámina ovada o elíptica, 20-105 x 10-53 mm, base cuneada o atenuada, a veces redondeada, ápice agudo, borde simple o doblemente aserrado-crenado, dientes subagudos, a veces con nectarios diminutos en las escotaduras; haz con epidermis rugosa, con pelos simples laxos, vena principal y 6-9 pares de venas laterales apenas salientes, pilosas, subopuestas o alternas, ángulo de divergencia $35-48^{\circ}$; envés villosotomentoso, con pelos simples largos, erectos y pelos glandulares estipitados, con cabeza diminuta, de color amarillo pálido; venas principales prominentes, divididas cerca del borde en dos ramas que enmarcan las escotaduras, venas terciarias visibles, venación menor inconspicua. Flores

Fig. 1.- Turnera aromatica A, rama con entrenudos cortos. B, rama vigorosa, con entrenudos bien desarrollados. C, porción del cáliz, cara externa. D, flor brevistila: porción del tuho calicino, cara interna, con pétalos y estambres adnatos (se ha cuadriculado la cicatriz dejada al desprender un estambre). E, flor brevistila: gineceo y profilos. F-G, semilla con arilo, vista lateral y desde el lado rafeal; a, arilo. H, pelo glandular. (A y H. Liesner \& al. 10710; B-G, Hunt 61). 


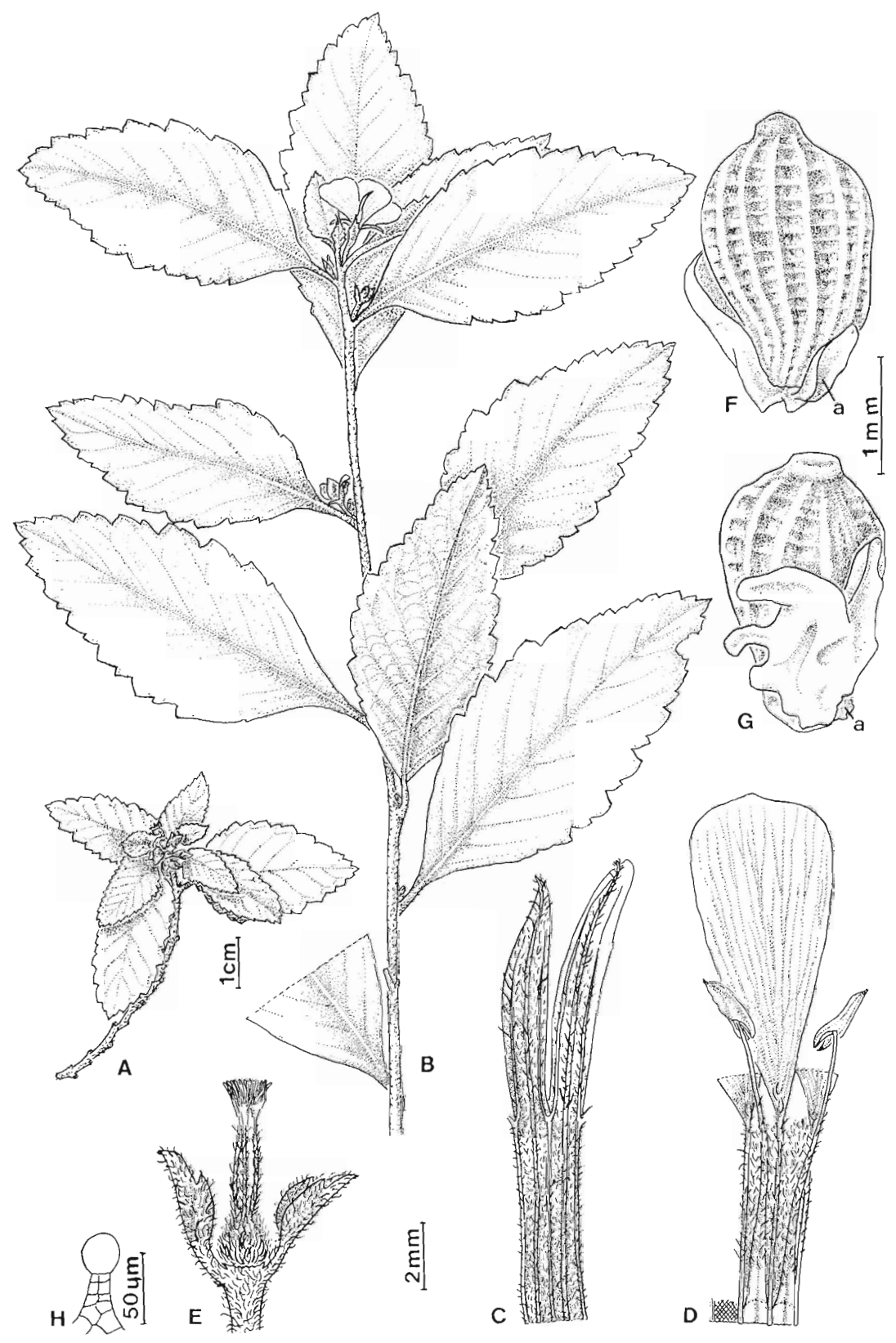


solitarias, axilares. Pedúnculo floral libre, 1-3 mm long., cilíndrico. Pedicelo no desarrollado. Profilos 2, situados en la base del cáliz, generalmente obovoides, a veces angustiovados o subulados, 4-5,5 x 1-3 mm, vellosos por fuera, por dentro glabros en la base, borde dentado. Cáliz 7-15 mm long., tubo 4,5-7 mm long., villoso por fuera, por dentro piloso hasta la garganta, lóbulos angustiovados o triangulares, por fuera con pelos largos, bordes internos membranáceos, mucrón 0,2-0,6 mm long. Corola 1,5$4 \mathrm{~mm}$ más larga que el cáliz, pétalos amarillos o anaranjados, uña pilosa, adnata al tubo calicino, lámina 8-10 x 4-7 mm, con un grupo de pelos en la base. Filamentos estaminales anchos en la base, soldados 0,6-1 $\mathrm{mm}$ al tubo calicino y engrosados en esa porción, luego subulados y pilosos, 4-5 mm long. en flores longistilas, 8-9 mm long. en flores brevistilas; anteras 1,5-2,3 x 0,4-0,6 mm, emarginadas en la base, ápice brevemente apiculado, filamento inserto en una cavidad basidorsal 0,6-0,7 mm long., rectas o recurvadas después de la dehiscencia. Ovario ovoide o suborbicular, 1-1,5 mm long., hirsuto, placentas 4-8 ovuladas, estilo cilíndrico, hirsuto, 2,5-5 mm long. en flores brevistilas, 6-7 mm long. en flores longistilas, estigma penicilado, glabro, 0,9-1,5 mm long. Fruto 2,5$5 \mathrm{~mm}$ long., valvas tuberculadas, pilosas por fuera, por dentro lisas o reticuladas, Iustrosas, amarillentas o a veces jaspeadas. Semilla 1,6-2,3 x 1,1-1,4 mm, obovoide, recta, a veces subglobosa, estriado-reticulada, muros longitudinales más salientes que los transversales, aréolas transrectangulares, epidermis con células papilosas; rafe linear convexa, cálaza ligeramente saliente, cóncava, pigmentada, exóstoma cónico muy corto; arilo 1,2-1,8 mm long., unilateral, ancho, lobado, células lisas.

Distribución: Especie con área disyunta, propia del extremo $\mathrm{S}$ de México, Belize y Guatemala y norte de América del Sur. Vive en sabanas, bosques de pinos, encinales y laderas secas, también en matorrales y bosques al borde de pantanos; prospera bien en lugares alterados con vegetación secundaria y aún en cultivos (café y camellones de arrozales). Vive desde el nivel del mar hasta una elevación aproximada a los $2200 \mathrm{~m}$. 
Nombre vulgar: "Skabon che" (Arnason \& al. 17151, Belize).

Paratipos: MEXICO. Quintana Roo: Mun. Chetumal, bajo de Morocoy, al E de Nicolás Bravo hacia Chetumal, 18.V.1980, Cowan 3030 (CAS, MO, NY); $6 \mathrm{~km} \mathrm{~N}$ de La Unión, 4.III.1980, Tellez \& al. 1657 (MEXU, MO).

BELIZE. Indian Church, 15.V.1976, Arnason \& al. 17151 (MO). Belize: Cornhouse Creek, Manatee R., 31.I.1931, Bartlett 11303 (F, MICH, US); Butcher Burn, Subun River, 4.I1.1931, Bartlett 11376 (F, K, MICH). Cayo: Along Hummingbird Hwy at mile 28,5, 14. VI. 1973, Dwyer 11219 (MO, P); Maskall Pine Ridge, I.1934, Gentle 1095 (F, K, MICH, MO, NY, S); Augustine, Mountain Pine Ridge, $16^{\circ} 34^{\prime} \mathrm{N}, 88^{\circ}$ 54' W, elev. 1500 ft, 31.VIII.1959, Hunt 61 (BM, US). Orange Walk: Honey Camp, Coastal Region, IX.1929, Lundell 432 (DS, MO, NY, US). Toledo: Swasey branch, Monkey river, 12.XI.1941, Gentle 3776 (MICH, MO, NY).

GUATEMALA. Izabal: Mun. El Estor, La Mina de Exmibal, al E del Estor, $15^{\circ} 31^{\prime} \mathrm{N} 89^{\circ} 23^{\prime} \mathrm{W}$, elev. $50 \mathrm{~m}, 17 . \mathrm{VII} .1988$, Tenorio \& al. 14588 (MO). Petén: Santa Elena, camino para el Remate, km 11, 15.V.1970, Tún Ortiz 1093 (BM, F, NY, US).

COLOMBIA. Magdalena: Cordillera Oriental, al E de Codazzi, camino hacia Machiques, elev. 400-1700 m, 17.III.1959, Romero-Castañeda 7559 (US). Santander: al $S$ de Bucaramanga, elev. ca. 500 m, 26.VIII.1948, Araque \& al. 275 (US).

VENEZUELA. Distrito Federal: Cordillera del Avila, dry south-facing slopes above Caracas, between Colegio Nacional de Enfermeras and Los Venados, elev. 10651520 m, 5.I.1944, Steyermark 55186 (NY). Falcón: Sierra de San Luis, arriba de Sta. María, elev. 1200 m, 30.VIII.1978, Wingfield \& al. 6625 (CTES). Mérida: Pueblos del Sur, elev. 1600-2200 m, VI.1955, Bernardi 2218 (CTES, NY). Nueva Esparta: Island of Margarita, El Valle, 30.VII.1901, Miller \& al. 266 (BM, F, K, MO, NY). Sucre: Isla de Arapo del Este (Arepito) $\mathrm{N}$ de Arapito, NW de Playa Colorado, $10^{\circ} 16^{\prime}$ N 64 28' W, elev. 0-10 m, 1.IX.1973, Steyermark \& al. 107902 (NY, US). Táchira: $7 \mathrm{~km} \mathrm{~W}$ of Rubio, $7^{\circ} 42^{\prime} \mathrm{N}, 72^{\circ} 25^{\prime} \mathrm{W}$, elev. 900-1000 m, 18.III.1981, Liesner \& al. 10710 (CTES, MO); Parque Cazadero, Quebrada Cazadero, 16 km NW of San Cristóbal, elev. 400-650 m, 7 54' N 72 18' W, 2.V.1981, Liesner \& al. 11685 (CTES, MO).

TRINIDAD. Chacachacare Island, 13.IV.1920, Britton \& al. 1722 (US, NY): St. Anna, Thomson s.n. (C).

Obs.: En varios ejemplares de herbario se indica que las hojas son aromáticas. En flores longistilas el gineceo es 1-3,5 mm más largo que el androceo; en flores brevistilas el androceo sobrepasa 3-4,5 $\mathrm{mm}$ al gineceo. Los filamentos estaminales son anchos en la base, los bordes llegan hasta la vena de los pétalos.

T. aromatica pertenece a la serie Annulares Urban. Es muy afín a $T$. breviflora Moura, que se distingue por sus hojas glabrescentes o con 
indumento laxo, y el tubo floral glabro o glabrescente en la base. T. odorata Richard, también emparentada, se diferencia por tener pelos glandulares capitados, sésiles, de color dorado o rojizo, y por sus hojas tomentosas con venas dispuestas en ángulo más abierto.

\section{Turnera candida Arbo nov. sp.}

Fig. 2

Turnera ulmifolia L. var. elliptica Urban, Jahrb. Königl. Bot. Gart. Berlin 2: 143, 1883. Typus. Brasil. Bahia, Tamandua, Blanchet 3832 (lectotipo, aquí designado, P!; isotipos!, BM, BR, G). Non T. elliptica Urban, Jahrb. Königl. Bot. Gart. Berlin 2: $107,1883$.

Fruticulus $50-60 \mathrm{~cm}$ altus, pilis simplicibus vestito, folia $3-7 \mathrm{~mm}$ longe petiolata, elliptica, ovata vel obovata, $2-7 \mathrm{~cm}$ longa, argute serrata; flores homostyli, pedunculo cum petiolo coalito; petala alba, interdum venis violaceis, filamenta cum marginibus nervis petalis adnata; fructus dorso granulosus; semina anguste obovata, 2,I-3 mm longa, manifeste reticulata, chalaza obtusa.

Typus. Brasil. Bahia, Livramento do Brumado, subida para Rio de Contas, sufrútice, flor alva, 6.IV.1992, G. \& M. Hatschbach \& E. Barbosa 56662 (holotipo, CTES; isotipo, MBM).

Sufrútice 50-60 cm de alto, ramas viejas 2-6 mm diám., con corteza parda o pardo-rojiza con grietas longitudinales blanquecinas; ramas cilíndridas, erguidas o ascendentes, las del año densamente estrigosas o cubiertas con pelos simples, largos y curvado-antrorsos, entrenudos 10-45 mm long. Yemas axilares 2-3 seriales, ramas seriales desarrolladas. Hojas herbáceas, recurvadas. Estípulas triangular-subuladas, 0,5-0,7 $\mathrm{mm}$ long. o reducidas a prominencias glandulares $0,1-0,3 \mathrm{~mm}$ long., escondidas en el indumento. Pecíolo semicilíndrico, 3-7 mm long., indumento igual que el del tallo. Nectarios $1+1$, raramente $1+20$ $2+2$, discoideos, elípticos o suborbiculares, 0,7-1,9 mm long., dispuestos en la unión de pecíolo y lámina, orientados hacia el envés, parte central cubierta por una membrana provista de un poro, frecuentemente ubicado en el cuadrante superior externo, reborde $0,1 \mathrm{~mm}$ lat., 


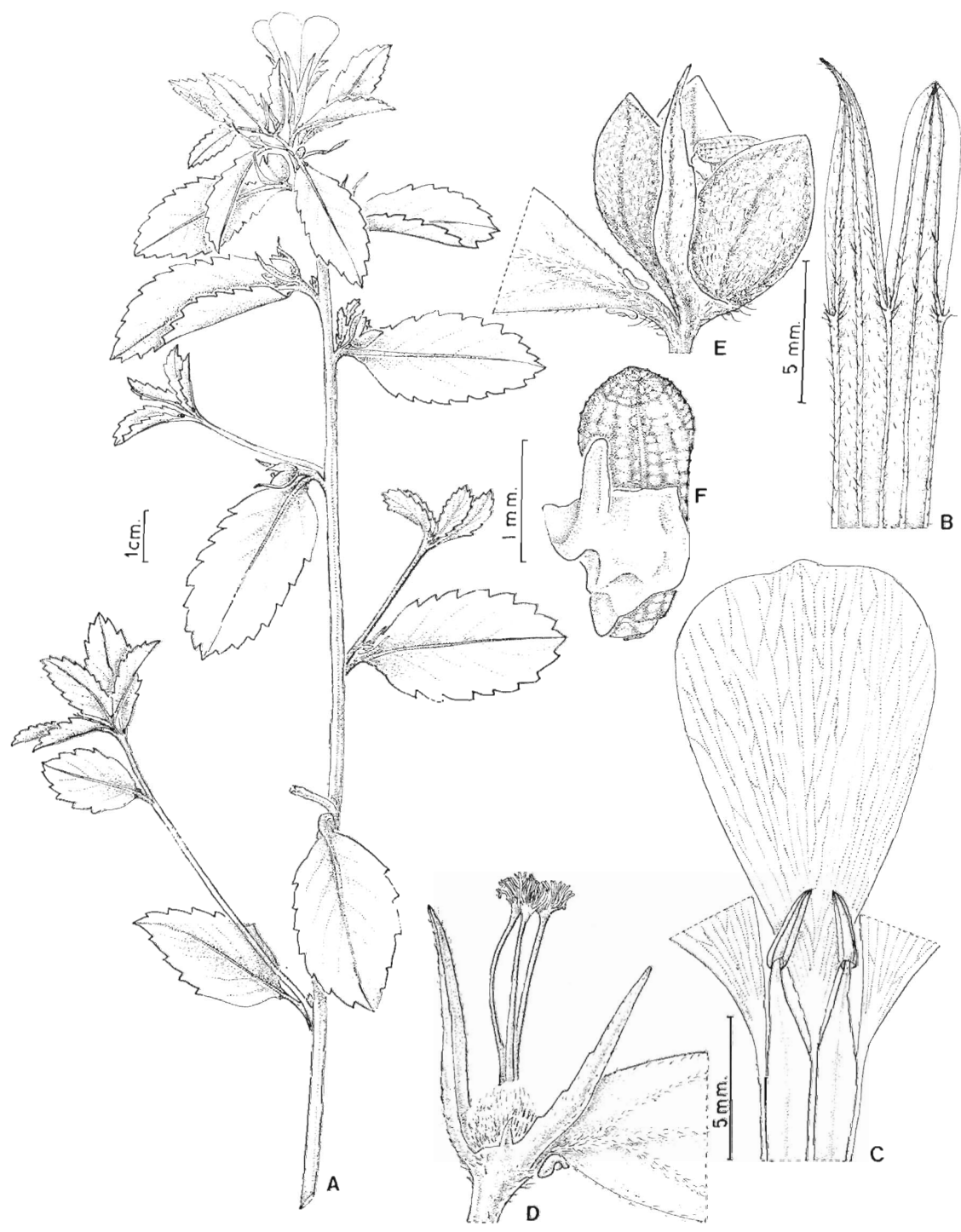

Fig. 2.- Turnera candida. A, rama florífera. B, porción del cáliz, cara externa. C, flor homostila: porción del tubo calicino, cara interna, con pétalos y estambres adnatos. $\mathrm{D}$, gineceo y profilos sobre la base de una hoja florífera. E, base de una hoja florífera con el fruto epifilo y los profilos persistentes. F, semilla con arilo, vista desde la rafe. (A y E, Harley \& al. 19892; B-D, Hatschbach 56825; F, Hatschbach 56641). 
amarillento, pilosiúsculo. Lámina elíptica, ovada, angustielíptica, angustiovada u obovada, extendida, 20-70 x 6-26 mm, relación largo: ancho $=1,8-3,6: 1$, base redondeada o anchamente cuneada, ápice agudo u obtuso, borde plano o ligeramente revoluto, aserrado excepto en el tercio inferior, dientes angostos, agudos, muy regulares; haz con pelos simples muy cortos, pelos glandulares capitados y pelos simples más largos orientados oblicuamente hacia afuera, envés con pelos glandulares y pelos simples erectos más laxos; vena principal y 5-7 pares de venas laterales ligeramente salientes en la haz, prominentes en el envés, alternas, con pelos largos antrorsos, ángulo de divergencia 30-50 venas terciarias más o menos perpendiculares a la vena media, generalmente inconspicuas, venación menor inconspicua. Flores solitarias, epifilas, homostilas. Pedúnculo 2-4 mm long., soldado totalmente al pecíolo. Pedicelo nulo. Profilos 5-12 x 0,8-1 (-2) mm, subulados, borde a veces ligeramente dentado, estrigosos. Cáliz 11-19 mm long., tubo calicino 5-8 mm long., por fuera estrigoso o con pelos simples, largos y curvado-antrorsos, lóbulos angustiovados, cara externa indumento como el tubo calicino, cara interna glabra, bordes internos membranáceos, mucrón apical 0,3-1,5 mm long. Corola 4-7 mm más larga que el cáliz, pétalos con la uña soldada al tubo calicino, lámina obovada 9-14 mm long., totalmente blanca o con venas violáceas. Filamentos estaminales complanado subulados, glabros, 6-8 mm long., soldados por los bordes $3,5-5 \mathrm{~mm}$ a la uña de los pétalos; anteras angustiovadas, $2-3 \times 0,3-0,5 \mathrm{~mm}$, basifijas, base emarginada, ápice obtuso. Ovario ovoide, hirsuto, 2-2,5 x 1,3-1,5 mm, placentas 14-17 ovuladas; estilos cilíndricos, 5,5-7 mm long., con algunos pelos simples hacia el ápice; estigmas penicilados, 1,5-2 mm long., ca. 12 ramas de diferente longitud. Fruto 4,5-8 mm long., verrucoso y estrigoso por fuera, lustroso, reticulado, verde-amarillento por dentro, con algunos pelos simples, vena placentaria no prominente. Semilla recta, obovoide, 2,1-3 x 0,7-1,2 mm, exóstoma cónico, rafe linear no saliente, cálaza obtusa, episperma reticulado, aréolas más o menos cuadrangulares, arilo pequeño, unilateral, más corto o poco más largo que la semilla. 
Distribución: Especie propia de "campo rupestre" y "cerrado rupestre", excepcionalmente hallada en "restinga" o "caatinga" (Joly, 1970); ha sido coleccionada solamente en Bahia y Minas Gerais.

Paratipos BRASIL. Bahia: $6 \mathrm{~km}$ SW de Mucugé, camino a Barra da Estiva, aprox. $13^{\circ} 01^{\prime} \mathrm{S} 41^{\circ} 26^{\prime} \mathrm{W}$, ca. $950 \mathrm{~m}, 25 . X I .1992$, Arbo \& al. 5764 (CTES, SPF); Desvío a Lençois, $8 \mathrm{~km} \mathrm{~S}$ de BR-242, $12^{\circ} 31^{\prime} \mathrm{S} 41^{\circ} 22^{\prime} \mathrm{W}$, ca. $500 \mathrm{~m}$, Arbo \& al. 5784 (CTES, SPF); Serra Jacobina, 1837, Blanchet 2613 en parte (BM, G, NY, $\mathrm{P}, \mathrm{W})$; ca. $1 \mathrm{~km} \mathrm{~S}$ of Mato Grosso on the road to Vila do Rio de Contas, ca.

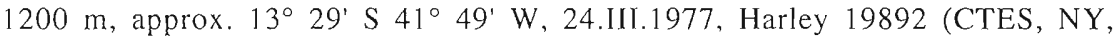
US); mun. Rio de Contas, povoado de Mato Grosso, arredores, $13^{\circ} 28^{\prime} \mathrm{S} 41^{\circ}$ $50^{\prime}$ W, 1260 m, 24.X.1988, Harley \& al. 25375 (CTES); Rio de Contas, $10 \mathrm{~km}$ N, 21.I.1984, Hatschbach 47440 (CTES); Serra do Sincorá, $15 \mathrm{~km} \mathrm{~S} \mathrm{de} \mathrm{Mu-}$ cugê, 22.I.1984, Hatschbach 47460 (CTES); Mun. Igaporã, Rod. BR-430, trevo para Tanque Novo, 1000 m, 5.IV.1992, Hatschbach \& al. 56641 (CTES, MBM); Rio de Contas: subida para Campo de Aviação, 1150 m, 6.IV.1992, Hatschbach \& al. 56713 y 56734 (CTES, MBM); Mato Grosso, 1300 m, 7.IV.1992, Hatschbach \& al. 56785 (CTES, MBM); rod. para Mato Grosso, 1100 m, 7.IV.1992, Hatschbach \& al. 56825 (CTES, MBM); Mun. Mucuri, km 6 da Rod. Mucuri/ Nova Viçosa, ramal a esquerda, 10 m, 20.V.1980, Mattos Silva \& al. 763 (CEPEC, CTES); Lençois, $12^{\circ} 34^{\prime} \mathrm{S} 41^{\circ} 23^{\prime} \mathrm{W}, 400-450 \mathrm{~m}$, 3.IV.1980, Noblick 1795 (CEPEC, CTES). Minas Gerais: $27 \mathrm{~km}$ by road NE of Diamantina, $2 \mathrm{~km}$ W of Rio Jequití, 790 m, 9.IV.1973, Anderson 8335 (NY); alrededores de Vau, $27 \mathrm{~km}$ SE de Diamantina, camino a Milho Verde, aprox. $18^{\circ} 23^{\prime} \mathrm{S} 43^{\circ} 31^{\prime}$ W, 15.II.1991, Arbo \& al. 5153 (CTES, SPF); mun. Cristalia, Rio Mumbuca, 11.11.1991, Hatschbach \& al. 55062 (CTES); monte Itambé [Morro Redondo], Martius s.n. (M); Grão-Mogol, córrego da Bonita, subida para o Morro Jambeiro, ca. $16^{\circ}$ 05' S 425' W, 7.XI.1990, Silva \& al. s.n., CFCR 13522 (SPF).

ARGENTINA. Corrientes, cultivada, proc. de Bahia, Livramento do Brumado, subida para Rio de Contas, XII.1992, Hatschbach \& al. 56662 bis (CTES).

Obs.: Cromosomas 2n $=10$ (Solís Neffa \& Fernández, 1993). Las flores pueden presentar el gineceo 0-2 mm más largo que el androceo. Los filamentos estaminales son tan largos como el tubo calicino, de manera que anteras y estigmas están en la garganta de la flor.

Especie perteneciente al complejo T. ulmifolia L., serie Canaligerae Urban (Arbo, 1985, 1986; Arbo \& Fernández, 1987). Las especies afines T. grandiflora (Urban) Arbo y $T$. caerulea DC., se diferencian por ser heterostilas. Son especies vicariantes, la primera es característica del chaco 
argentino-paraguayo, mientras la segunda tiene área disyunta, encontrándose en la "caatinga" brasileña, Bolivia y Guayanas así como en México y el sur de EE.UU.

\section{Turnera cipoensis Arbo nov. sp.}

Fig. 3

Herba vel suffrutex $8-40 \mathrm{~cm}$ altus, folia $0,5-3 \mathrm{~mm}$ longe petiolata, elliptica, lanceolata vel ovata, 6-33 $\mathrm{mm}$ longa, utrinque subglabra, margine revolutis; flores heterostyli, pedunculo $2-5 \mathrm{~mm}$ longo, cum petiolis coalito; calyx 8,5-13 mm longus, corolla flava; filamenta plerumque pilosa, basi tubo tota facie adnata; semina 2-2,5 $\mathrm{mm}$ longa, curvata, nodis reticuli modice prominentibus.

Typus: Brasil, Minas Gerais, 7 km NE de Cardeal Mota, camino a Conceição do Mato Dentro, $19^{\circ} 20^{\prime} \mathrm{S} 43^{\circ} 35^{\prime} \mathrm{W}, 1000-1320 \mathrm{~m}$, campo rupestre, suelo arenoso, rocas cuarcíticas; entre piedras, en lugares húmedos, en cerrado; flores amarillas heterostilas, 8.Il.1991, Arbo M.M., N.L. Menezes, A. Schinini \& M.T.V.A. Campos 4631 (holotipo, SPF; isotipos, CTES, F, GH, K, MBM, MO).

Hierba perenne o subarbusto erecto, $8-40 \mathrm{~cm}$ alt., base leñosa $1-10$ mm diám., tallos 1-6, frecuentemente ramificados desde cerca de la base, cilíndricos, castaños o negruzcos en la base, luego verdes, 1-2,5 mm diám., glabrescentes en la parte inferior, luego densamente estrigosos (pelos simples, cortos, gruesos, curvado-antrorsos, amarillentos), entrenudos 0,1-22 mm long., más cortọs en la región distal. Hojas herbáceas, erectas a patentes. Estípulas reducidas a prominencias cónicas, rojizas, 0,2-0,4 mm long., con un mechón de pelos. Pecíolo estrigoso, 0,5-3 mm long. Nectarios $1+1$, raramente $1+2$ o $2+2$, ubicados en la unión de pecíolo y lámina o

Fig. 3.- Turnera cipoensis. A, planta. B, nudo y porción basal de la hoja mostrando el envés, con los nectarios y el borde revoluto. C, flor brevistila, porción de la cara interna del tubo calicino con pétalos y un estambre adnatos; se han cuadriculado las cicatrices dejadas al desprender los estambres. D, gineceo. E, nudo y porción basal de una hoja con fruto y profilo sobre la haz y mostrando un nectario en el envés. $F$, semilla con arilo, vista desde el lado opuesto a la rafe; a, arilo. n, nectario. (A-E, Maguire \& al. 44693a; F, Palacios \& al. 3590). 

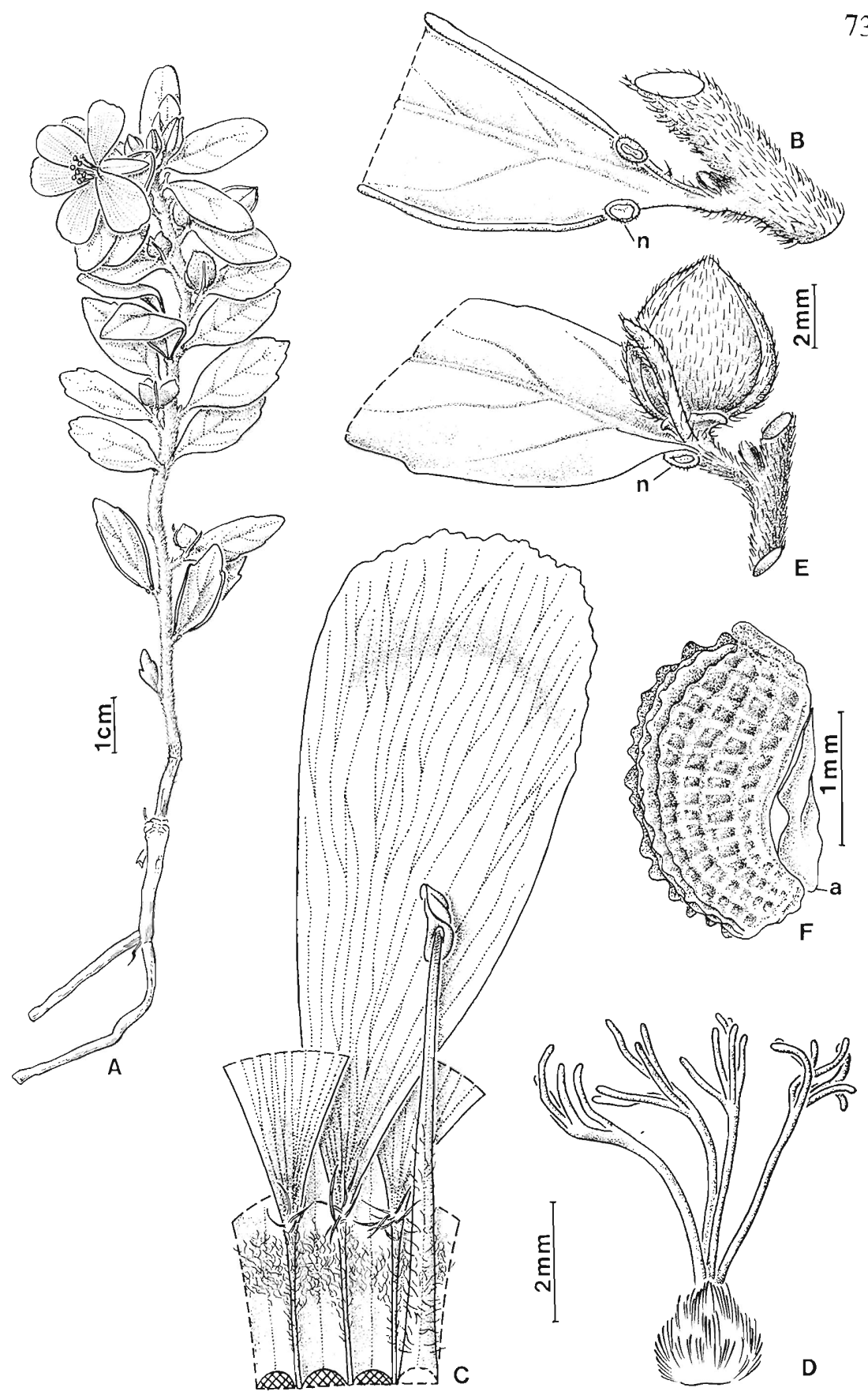
desplazados 0,5-2 mm sobre el borde de la lámina, circulares o elípticos, 0,4-1,2 mm long., reborde glabro o pubérulo, generalmente amarillento, centro obscuro cubierto con una membrana. Lámina verde en seco, elíptica, lanceolada, ovada, a veces largamente obovada, 6-33 x 2-13 mm, relación largo: ancho $=1,7-5: 1$, con pelos simples adpresos a veces solamente sobre las venas; base cuneada o atenuada, ápice agudo, borde revoluto, entero o aserrado en la porción apical (hasta 70\% de su longitud), glabro o piloso, dientes de aspecto glanduloso; haz punteada, a veces lustrosa, 2-5 pares de venas laterales, salientes en ambas caras, opuestas o alternas, ángulo de divergencia $35-50^{\circ}$, venación menor inconspicua. Flores heterostilas, epifilas. Alabastro elipsoide, recto, mucrones libres en el ápice. Pedúnculo 2-5 mm, totalmente soldado al pecíolo y a veces a la vena media. Pedicelo ausente. Profilos opuestos, dispuestos en la base del receptáculo, subulados o triangulares, 2,5-5 x 0,4-1 mm, estrigosos por fuera, borde liso o con 1-4 dientes glandulosos a cada lado, ápice agudo, con pelos. Cáliz 8,5-13 mm long., tubo calicino 2,5-4 mm long., estrigoso por fuera, velloso por dentro, lóbulos triangulares o lanceolados, por fuera con pelos simples, largos, curvado-antrorsos, por dentro glabros, bordes internos membranáceos y a veces purpúreos, ápice con mucrón 0,3-0,5 mm long. Pétalos con uña vellosa, lámina obovada, amarilla, 10-14 x 4,7-8 mm, base pilosa por dentro, ápice obtuso. Filamentos estaminales con pelos simples blandos en la cara interna o en ambas, a veces glabros, soldados en la base por 0,3-0,5 $\mathrm{mm}$ al tubo calicino, 4,5-6 $\mathrm{mm}$ long. en flores longistilas, 7$8,5 \mathrm{~mm}$ long. en flores brevistilas; anteras ovadas, dorsifijas, 1,2-2 x 0,5$0,8 \mathrm{~mm}$, base emarginada, ápice obtuso, rectas o ligeramente curvadas después de la dehiscencia, filamento inserto en una concavidad dorsal $0,5-$ 0,7 mm long. Ovario cónico, 1,1-2 mm long., densamente cubierto de pelos gruesos, rígidos, placentas ca. 8-ovuladas; estilos cilíndricos, glabros, 4,5-6 mm long. en flores longistilas, 2,5-3,3 mm long. en flores brevistilas, estigmas 1,5-3 mm long., divididos en 8-18 ramas cilíndricas. Fruto esferoidal o elipsoidal, a veces apiculado, 3-7 x 3-5 mm, valvas ovadas, dehiscentes hasta la base, pilosas por fuera, glabras y jaspeadas por dentro, absición de los restos florales a 0,3-0,5 $\mathrm{mm}$ de la base dejando un reborde 
alrededor de la base del fruto. Semilla obpiriforme, curvada, castaña, 2-2,5 x 1,2-1,5 mm, reticulada, episperma reticulado, aréolas cuadrangulares o rectangulares, nudos ligeramente prominentes en general, epidermis glabra, células papilosas; cálaza un poco saliente, pigmentada; rafe linear; exóstoma cónico; arilo membranáceo en seco, 1-1,5 mm long., células lisas.

Distribución: Especie aparentemente endémica de la Serra do Cipó, Minas Gerais, donde crece en campos de altura o "campos rupestres" a 1000-1300 m de elevación.

Paratipos: BRASIL. Minas Gerais. Serra do Cipó: 10-20 km NE de Cardeal Mota, camino a Conceição do Mato Dentro, $19^{\circ} 20^{\prime} \mathrm{S} 43^{\circ} 35^{\prime} \mathrm{W}, 1000-1320 \mathrm{~m}$, 15.V.1990, Arbo \& al. 4117 (CTES, SPF); km 131, Palacio, 3.XII, 1949, Duarte 2080 (RB); ca. km 120, ca. $145 \mathrm{~km} \mathrm{~N}$ of Belo Horizonte, $1200 \mathrm{~m}, 15 . I I .1968$, Irwin \& al. 20104a (CTES, NY, US); Mun. Jaboticatubas, ao longo da rodovia Lagoa Santa Conceição do Mato Dentro - Diamantina, km 116, 1175 m, 6.VI.1970, Joly \& al. 109 (SP): Serra Cipó between km 111 and 128, 20.XII.1959, Maguire \& al. 44693a (NY); Conceição, Fazenda Palacio, 1200 m, 22.XII.1948, Palacios \& al. 3590 (LIL); 1200-1300 m, 16.III.1964, Pereira 8897 (RB); Mun. Jaboticatubas, ao longo da rodovia Lagoa Santa - Conceição do Mato Dentro - Diamantina, km 127, Semir \& al. 494 (NY, SP); km 114, 24.V.1972, Semir \& al. 2774 (SP).

Obs. T. cipoensis pertenece a la serie Leiocarpae Urban por sus frutos lisos y su morfología floral. Es afin a $T$. riedeliana Urban, que se diferencia por su porte menor, y sus hojas lineares, también con margen revoluto. T. oblongifolia Cambess., de aspecto similar, se diferencia por sus hojas con margen plano y más consistentes, y sus filamentos estaminales glabros.

Igual que en otras especies, algunas veces se encuentran flores con gineceo formado por cuatro carpelos.

\section{Turnera gardneriana Arbo nov. sp.}

Fig. 4

Frutex 0,9 m altus, folia 2-4 mm longe petiolata, ovata vel elliptica, 25-40 mm longa, supra tomentosa, subtus lanosa, florifera celeriter decrescentibus; flores 
verisimiliter homostyli, in racimo apicalli collectis, pedunculo brevissimo, prophyllis ellipticis, $10 \mathrm{~mm}$ longis; calyx $12-13 \mathrm{~mm}$ longus, filamenta cum marginibus nervis petalis adnata.

Typus: Brasil, Goiás, Serra do Duro [actualmente Dianópolis], IX.1839, Gardner G. 3029 (holotipo, K).

Arbusto $90 \mathrm{~cm}$ alt., corteza pardo negruzca longitudinalmente estriada, cicatrices foliares ligeramente salientes; ramas del año tomentosohirsutas, con pelos crespos cortos y pelos largos; estípulas cónicas o subuladas, rojizas, 0,3-0,4 mm long., escondidas entre el indumento; yemas axilares y ramas seriales no observadas. Pecíolo semicilíndrico, 2-4 mm long., indumento como el del tallo. Lámina foliar ovada o elíptica, 25$40 \times$ 20-25 mm, relación largo: ancho $=1,3-1,6: 1$, base redondeada u obtusa, ápice obtuso, borde aserrado-crenado, dientes grandes, obtusos o agudos, haz pardo-rojiza en hojas viejas, densamente pilosa, tomentosa en hojas nuevas, envés lanoso, castaño claro, venas laterales 6-8, alternas o subopuestas, ángulo de divergencia $40-50^{\circ}$, hundidas en la haz, prominentes en el envés, perdiéndose hacia el margen y emitiendo ramas hacia los dientes, con pelos largos, antrorsos, amarillentos, venas terciarias hundidas en la haz, inconspicuas en el envés, venación menor inconspicua. Flores probablemente homostilas agrupadas en racimos apicales. Hojas floríferas súbitamente decrecientes, 10-12 x 4-8 mm, brevemente pecioladas, margen liso en la porción basal, luego con dientes agudos, densamente pilosas en ambas caras. Pedúnculo 0,5 mm long., aparentemente libre. Profilos insertos en la base del receptáculo, 10 × 2-2,5 mm, elípticos, con 1-2 dientes cerca del ápice agudo, pilosos en ambas caras. Cáliz 12-13 mm long., tubo $7 \mathrm{~mm}$ long., tomentoso por fuera, velloso por dentro, lóbulos triangulares, 3-5-nervados, cara externa con indumento como en el tubo, cara interna glabra, bordes internos membranáceos, glabros, mucrón 0,3 mm long, con pelos largos. Corola 1-2 mm más larga que el cáliz, pétalos con la uña soldada al tubo calicino, lámina obovada, con algunos pelos en la base de la cara adaxial, 9,5-12 x 4-4,5 mm. Filamentos estaminales complanado-subulados, glabros, $6 \mathrm{~mm}$ long., soldados por sus bordes $3,5 \mathrm{~mm}$ a la uña de los pétalos; anteras angustiovadas, 3,3 

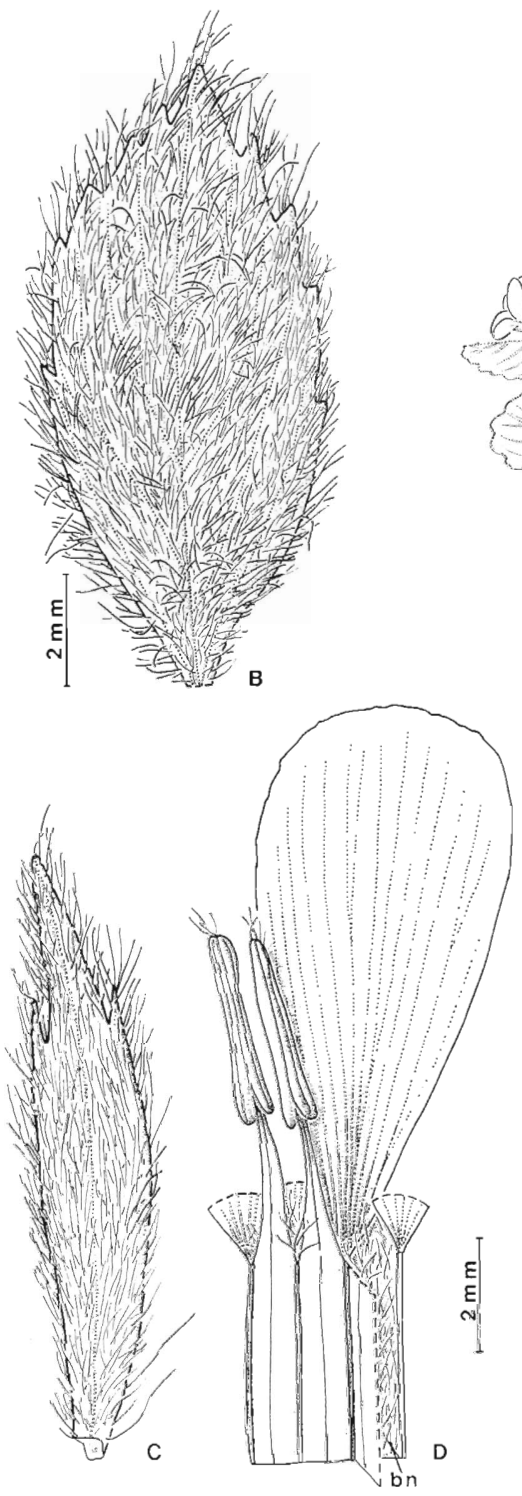

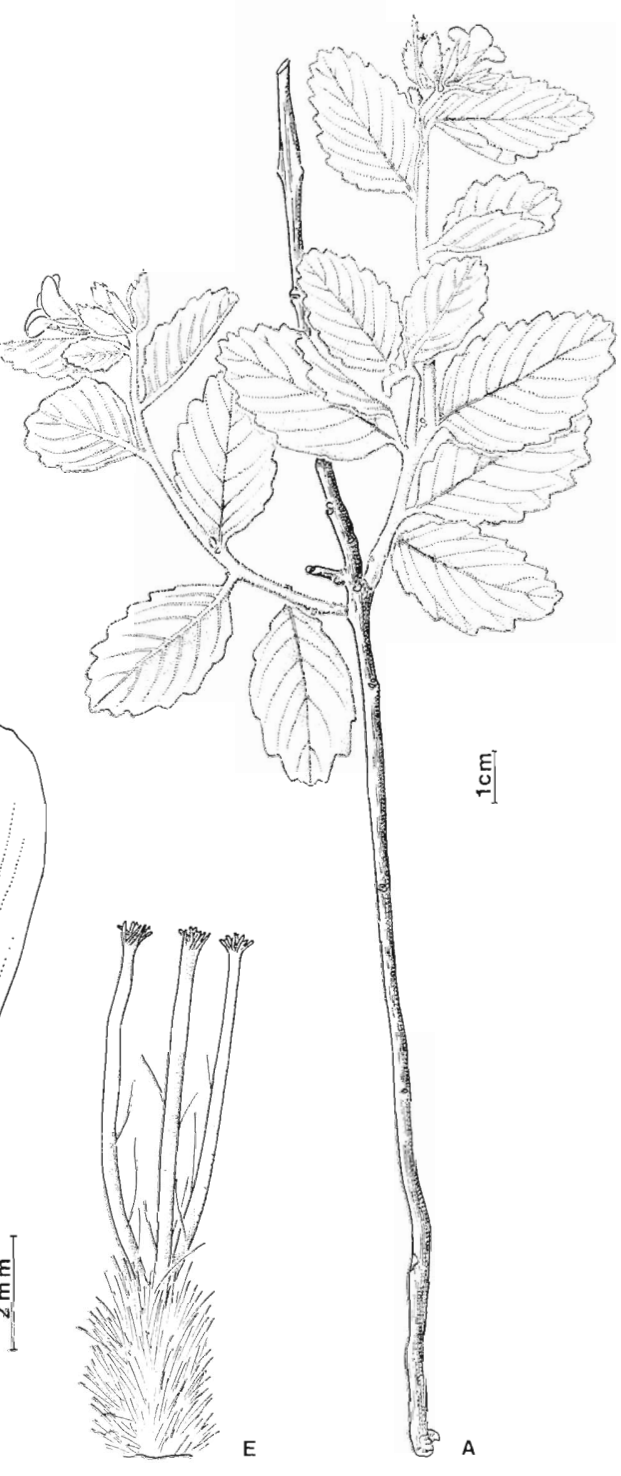

Fig. 4. Turnera gardneriana. A, planta. B, hoja florífera vista desde la haz. C, profillo. D, flor homostila: porción de la cara interna del tubo calicino, con pétalo y estambres adnatos; se ha desprendido uno de los bordes de la porción basal del filamento estaminal para mostrar el interior del bolsillo nectarífero. E, gineceo. bn, bolsillo nectarífero (Gardner 3029). 
x 0,6 mm, basifijas, ápice recto después de la dehiscencia, brevemente apiculado, con algunos pelos cortos. Ovario ovoide, hirsuto, $2,5 \times 1,5 \mathrm{~mm}$; estilos cilíndricos, $6 \mathrm{~mm}$ long., con algunos pelos largos sobre el lado interno; estigma penicilado, ca. 8 ramas $0,4-0,5 \mathrm{~mm}$ long. Fruto y semilla no observados.

Obs.: A pesar de no conocerse el fruto y la semilla de T. gardneriana, los filamentos estaminales soldados por sus bordes a la uña de los pétalos y la presencia de un brevísimo pedúnculo floral libre, indican que pertenece a la serie Anomalae Urban. T. cearensis Urban, hasta ahora la única especie de la serie, se reconoce fácilmente por presentar pelos estrellados.

Por su aspecto vegetativo la planta se parece a $T$. waltherioides Urban, de la serie Capitatae Urban, que se diferencia por sus flores pequeñas, con filamentos estaminales no soldados por los bordes, dispuestas en inflorescencias laterales.

Urban determinó el tipo, con dudas, como T. longiflora Cambess., tal vez por sus flores grandes, de color probablemente escarlata, semejantes a las de dicha especie, perteneciente a la serie Leiocarpae, con diferente estructura floral.

\section{Turnera joelii Arbo nov. sp.}

Fig. 5

Frutex 0,3-0,8 m altus, folia $1-4$ (-13) mm longe petiolata, ovata, elliptica vel obovata, 13-42(-85) mm longa, nectariis discoideis 0,3-0,7 mm longis praedita, supra glabra, subtus pilis capitatis flavis secernentibus sparsis; flores heterostyli, pedunculo cum petiolo coalito; calyx $15-16 \mathrm{~mm}$ longus, corolla flava, filamenta cum marginibus nervis petalis adnata; fructus dorso granulosus; semina arcuato-curvata, 2,4-3 mm longa, manifeste reticulata, chalaza breve ad raphem spectante prominente concava.

Typus: Brasil, Bahia, $29 \mathrm{~km} \mathrm{~S}$ de Juazeiro, BR-407, 09 48' S $40^{\circ} 20^{\prime} \mathrm{W}, 410$ m, flor amarilla, 11.IV.1983, Krapovickas A., J.F.M. Valls, R.F.A. Veiga \& G.P. Silva 38793 (holotipo, CEN; isotipos, CTES, K, MBM, NY). 
Subarbusto ramificado $30-80 \mathrm{~cm}$ alt., raíz fasciculada con un eje y numerosas ramas laterales; tallos con corteza castaña o rojiza, longitudinalmente agrietada o estriada, ramas cilíndricas erguidas o ascendentes, 1-2 mm diám., cicatrices foliares salientes, ramas del año con pelos simples, curvado-antrorsos, cortos. Yemas axilares 1-3 seriales. Ramas seriales desarrolladas. Hojas herbáceas, reflexas en vivo, frecuentemente plegadas longitudinalmente en seco. Estípulas cónicas, 0,1-0,3 mm long., pilosas. Pecíolo semicilíndrico, 1-4(-13) mm long., indumento como el de] tallo. Nectarios $1+1$, discoideos, suborbiculares o elípticos, 0,3-0,7 mm long., sésiles o brevemente estipitados, dispuestos en la unión de pecíolo y lámina o desplazados sobre el margen de la lámina, orientados hacia el envés, parte central cubierta por una membrana con un poro, reborde 0,1 $0,2 \mathrm{~mm}$ lat., amarillento o rojizo, glabro o pilosiúsculo; lámina ovada, elíptica u obovada, 13-42(-85) x 5-18(-40) mm, relación largo:ancho = 3,2$2,3: 1$, base atenuada o cuneada, ápice agudo, a veces obtuso, margen plano, glabro o estrigoso, aserrado excepto en la porción basal, dientes agudos u obtusos; haz punteada, ligeramente rugosa en seco, glabra (o con pelos simples, cortos, antrorsos, adpresos, laxamente dispuestos), vena media ligeramente saliente, estrigosa en la porción basal; envés con pelos glandulares esparcidos, diminutos, capitados y subsésiles, 5-7 pares de venas laterales visibles en la haz, ligeramente salientes y estrigosas en el envés, ángulo de divergencia ca. $25^{\circ}$, rectas o ligeramente incurvas, dando antes del borde ramas que inervan los dientes; venas terciarias y venación menor apenas visibles en el envés. Alabastros elipsoides, agudos, rectos con los mucrones del cáliz libres en el ápice. Flores heterostilas. Pedúnculo 2$4,5 \mathrm{~mm}$ long., totalmente adnato al pecíolo o libre hasta $2 \mathrm{~mm}$ en el ápice, piloso; receptáculo plano o ligeramente cóncavo en la parte superior, 1-2 mm diám. Profilos linear-subulados, 5,5-8 x 0,4-0,6 mm, verdes (rojizos o con bordes rojizos), cara externa estrigosa, cara interna glabra, borde entero o serrulado. Cáliz infundibuliforme, 15-16 mm long., tubo 5,5-6 mm long., verde o purpúreo, estrigoso por fuera, velloso por dentro en la garganta, lóbulos triangulares o angustiovados, agudos, verdosos y estrigosos por fuera, glabros por dentro, bordes internos membranáceos, hialinos, (a 
veces rojizos), ápice agudo, terminado en un mucrón $0,7-1,2 \mathrm{~mm}$ long. Pétalos amarillo-dorados, sedeños, uña glabra, adnata al tubo del cáliz, lámina obovada, 17-19 x 8-13 mm, base cuneada, ápice redondeado, eroso. Filamentos estaminales complanado-subulados, glabros, soldados por 2,7$3 \mathrm{~mm}$ a la uña de los pétalos, 6-6,5 mm long. en flores longistilas, 10,5 $\mathrm{mm}$ long., en flores brevistilas; anteras angustiovadas, $2 \times 0,4-0,5 \mathrm{~mm}$, base emarginada, ápice agudo, recurvado a la dehiscencia, filamento inserto en una cavidad basi-dorsal a $0,5 \mathrm{~mm}$ de la base. Ovario ovoide, $1,5-1,8 \times 1$ $\mathrm{mm}$, densamente cubierto de pelos simples, largos, erectos, placentas 610-ovuladas; estilos cilíndricos, 8,5-9,7 mm long. en flores longistilas, 3,5 $\mathrm{mm}$ long. en flores brevistilas, con pelos simples esparcidos sobre la cara interna; estigmas ca. 12 ramas de 0,8-2 mm long. Fruto ovoide, $5 \mathrm{~mm}$ long. receptáculo ligeramente cóncavo, en cuyo borde se observa la cicatriz angosta, 0,1 mm lat., dejada por el tubo floral al desprenderse; valvas ovadas, ápice agudo, cara externa granulosa, con pelos simples, largos, erguidos, cara interna glabra, lustrosa, reticulada, vena placentaria prominente, a veces oscura. Semilla obovoide, curvada, 2,4-3 x 0,7-1 mm, relación largo: ancho = 3-3,4:1, negruzca a la madurez, reticulada, muros longitudinales bien marcados, aréolas cuadrangulares o transrectangulares, ca. 0,15 x 0,15 mm, exóstoma hemisférico, 0,3-0,4 mm long., rafe linear marcada, cálaza breve, $0,1 \mathrm{~mm}$ long., prominente, formando un rodete, ápice plano, cóncavo, orientado hacia la rafe; arilo unilateral, borde lobulado, más corto que la semilla, de células no papilosas, blanquecino o castañoamarillento en seco.

Distribución: Planta propia de la "caatinga" brasileña, hasta el momento coleccionada solamente en el norte de Bahía; crece bien en lugares modificados como los bordes de los caminos.

Fig. 5.- Turnera joelii. A, rama florífera. B, flor longistila: porción de la cara interna del cáliz, con pétalos y estambres adnatos. C, porción basal de una hoja, con gineceo y profilos sobre la haz. D, semilla con arilo, vista lateral. n: nectario (Arbo $\&$ al. 2555). 
Nuevas especies de Turnera
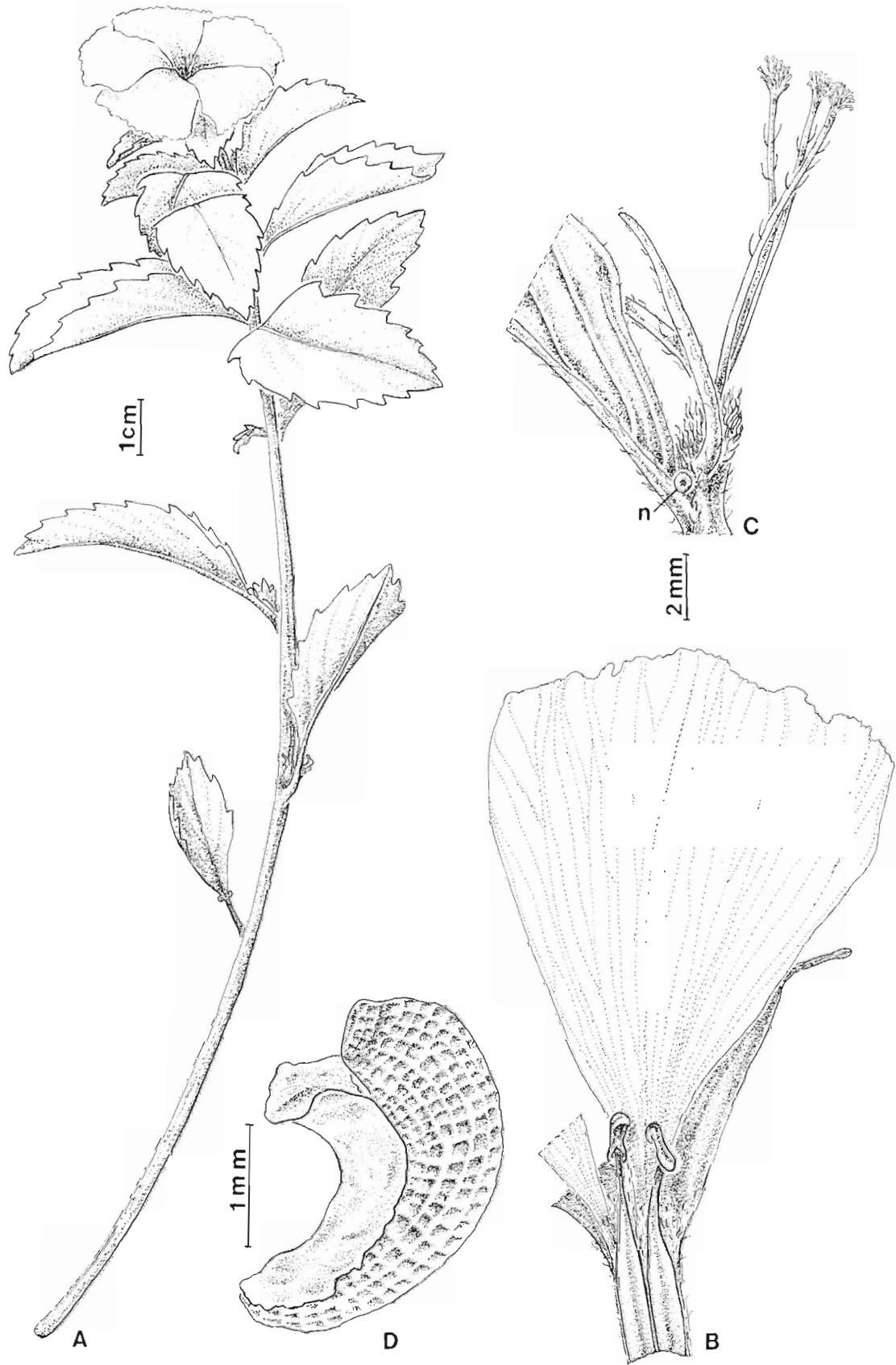
Nombre vulgar: "curicaca" (Pinto \& al. 196); "malvinha de Lagoa" (Ferreira 100).

Paratipos: BRASIL. Bahia: $37 \mathrm{~km}$ WNW de Irecê, camino a Xique-Xique, 28XI-1992, Arbo \& al. 5349 (CTES, SPF); Rio Juremal, Barrett \& Shore 1373 (CTES); mun. Juazeiro, $11 \mathrm{~km} \mathrm{~S}$ of city of Juazeiro, $0,5 \mathrm{~km} \mathrm{~S}$ of Rio Juremal, in JuazeiroFeira de Santana highway, 09 44' S 40 21' W, 380 m, 8.III.1970, Eiten \& al. 10874 (NY, SP, US); Irecê, Lagoa dos Patos ca. $27 \mathrm{~km} \mathrm{~S}$ de Irecê, 20.VIIl.1980, Ferreira 100 (CTES); Campo Formoso, $10^{\circ}$ 17' S 40 39' W. 21.IV.1981, Fonseca 374 (CTES); mun. Cafarnaum, Mulungu do Morro, 13.X.1981, Hatschbach 44230 (CTES); entre Carnaiba e Juremal, Juazeiro, Leal Costa s.n. (CTES); Irecê, prox. a Baixoes de Cima, Rumo ao Algodão, 21.VIII.1980, Oliveira 233 (MO); próximo a cidade de Curaçá, $09^{\circ} 01^{\prime} \mathrm{S} 39^{\circ} 55^{\prime} \mathrm{W}, 9 . \mathrm{VIII} .1983$, Pinto \& al. 196 (K, NY); cerca de $5 \mathrm{~km}$ de Bendengo, 21.V.1978, Souza Silva 594 (CTES); Canudos, 9.VII.1951, Travassos 102 (RB); Juazeiro, 28.IV.1973, Valeriano s.n. (CTES).

ARGENTINA. Corrientes, cultivado, de semillas de Krapovickas \& al. 38793. 1.XII.1983, Arbo \& al. 2555 (CTES).

Obs.: Cromosomas $2 \mathrm{n}=10$ (Arbo \& al. 2555, Barrett \& Shore 1373, Hatschbach 44230, Krapovickas \& al. 38793). En Hatschbach 44230 se contaron 20 y 40 cromosomas en puntas de raíces secundarias. Citada como Turnera aff. coriacea Urban (Arbo \& Fernández 1987; Fernández 1987).

Plántula de hipocótilo bien desarrollado con pelos simples; cotiledones peciolados, lámina elíptica, entera, glabra; las hojas al ser estrujadas despiden un olor intenso, desagradable; las flores son suavemente perfumadas, con androceo o gineceo apenas exsertos (Arbo \& al. 2555). Se han observado agallas de forma ahusada en los tallos (Ferreira 100). En flores longistilas el gineceo es 3-5 mm más largo que el androceo; en flores brevistilas el androceo es 3-6 mm más largo que el gineceo.

$T$. joelii pertenece a la serie Canaligerae; tiene aspecto vegetativo similar al de T. lucida Urban, que se diferencia por sus flores homostilas, de tamaño menor, y sus semillas con cálaza redondeada, no prominente y apical. Es afín a $T$. coriacea Urban y a $T$. simulans Arbo (Arbo, 1981), cuyas semillas son tenuemente reticuladas, con cálaza prominente de ápice oblicuo; la primera especie, con nectarios foliares de tamaño notablemente mayor, vive en campos rupestres y cerrados de Minas Gerais, y la segunda con hojas pequeñas, eglandulosas o con nectarios diminutos, es 
propia de campos rupestres del sur de Bahia. $T$. joelii se diferencia de todas las especies de este grupo por sus semillas con muros del retículo salientes, su cálaza breve, en forma de rodete, y el arilo formado por células lisas.

Dedico esta especie al Dr. Joel Shore, quien ha publicado trabajos sobre la biología reproductiva de varias especies de Turnera, y con quien he intercambiado material e información.

\section{Turnera prancei Arbo nov. sp.}

Fig. 6

Turnera riedeliana auct. non Urban en Hoehne, Hist. Nat. Bot. 6: 53, 1915. Hoehne, Inf. Com. Rondon: 290, 1951.

Herba graminifolia $25-45 \mathrm{~cm}$ alta, caule terete glabrato, vel pube simplice subfoliorum insertione longitudinaliter disposita. Folia linearia vel lanceolata, acuta, supra glabra, subtus ad nervo medio pilosa, nervis utrinque prominentibus. Flores heterostyli; pedunculi petiolo adnati; pedicelli nulli; calyx $6,5-7,5 \mathrm{~mm}$ longus, ad lobos pilosus; petala flava, filamenta glabra, basi tubo tota facie adnata.

Typus. Brasil, Mato Grosso, BR-163, km 768,5, $10 \mathrm{~km} \mathrm{~S}$ of Mato Grosso-Pará border, $490 \mathrm{~m}$ alt., open rocky area, herb $20-40 \mathrm{~cm}$ tall, corolla yellow, 12.XI.1977, Prance G.T., A.S. Silva, C.C. Berg, A.J. Henderson, B.W. Nelson, M. Balick, R.P. Bahia, M.R. dos Santos 25281 (holotipo, CTES; isotipo, NY).

Hierba erecta, graminiforme, perenne, $25-45 \mathrm{~cm}$ alt., base leñosa de 1-3 mm diám., tallos 1-varios, poco ramificados, cilíndricos, sinuosos, grises o castaños en la base, luego verdes, longitudinalmente estriados, punteados, 0,7-2 mm diám., glabros o con algunos pelos en la base y pelos adpresos dispuestos en filas debajo de la inserción de las hojas, entrenudos 4-35 mm long. Hojas cartáceas, extendidas, lustrosas, verdes en seco, sésiles o brevemente pecioladas. Estípulas ausentes o reducidas a prominencias cónicas, rojizas, $0,1 \mathrm{~mm}$ long. Nectarios 1-2, discoideos, 0,3-0,7 mm diám., situados sobre el margen foliar, a 1-2,5 mm de la base, reborde glabro o apenas pubérulo, porción central con una membrana provista de un poro central. Lámina linear o lanceolada, 10-46 x 0,7-2,5(-5) mm, re- 
lación largo:ancho (6-)9-30:1, base cuneada, ápice agudo, borde plano, entero o denticulado, glabro excepto el ápice con 2-3 pelos, haz punteada, glabra, envés glabro o con algunos pelos en la base y sobre la vena media, 3-5 pares de venas laterales prominentes en ambas caras, decurrentes, ángulo de divergencia $10-12^{\circ}$, venación menor visible en ambas caras. Flores solitarias, heterostilas, epifilas, dispuestas en la porción distal de los ejes simulando un racimo hojoso de hasta $24 \mathrm{~cm}$ long. Alabastro elipsoide, ápice agudo, mucrones libres en el ápice. Pedúnculo 2-6 mm long., glabro o estrigoso, totalmente soldado a la vena media o con una porción apical libre de 0,5-2,5 mm long. Profilos situados en la base del receptáculo o ligeramente distantes, subulados, 2,5-3 x 0,3-0,5 mm, glabros o con algunos pelos. Cáliz 6,5-7,5 mm long., con pelos simples, adpresos, en la base, sobre las venas y en el ápice de los lóbulos; tubo campanulado, 2-3 mm long., velloso por dentro; lóbulos angustiovados, ápice acuminado, a veces purpúreo, mucrón 0,2-0,4 mm long. Pétalos amarillos con la uña vellosa, adnata al tubo, lámina obovada, 8-10 x 3-5 mm, base atenuada, ápice obtuso o apiculado. Filamentos estaminales subulados, glabros, 3,5-5,5 $\mathrm{mm}$ long. en flores longistilas, $6 \mathrm{~mm}$ long. en flores brevistilas, base soldada al tubo 0,5-0,6 mm; anteras ovado-elípticas, 1-1,2 x 0,4-0,6 mm, base emarginada, ápice obtuso, ligeramente curvadas después de la dehiscencia, filamentos insertos en una cavidad basidorsal de 0,3-0,5 mm long. Ovario cónico, 1-1,5 mm long., hirsuto; estilos cilíndricos, 3,5-4,5 mm long. en flores longistilas, $2 \mathrm{~mm}$ long. en flores brevistilas, glabros o con algunos pelos; estigmas divididos en 4-6 ramas 1,2-2 $\mathrm{mm}$ long. Fruto y semilla desconocidos.

Distribución: Especie coleccionada hasta el momento solamente en los estados de Mato Grosso y Rondonia.

Fig. 6.- Turnera prancei. A, rama florífera. B, detalle de un nudo, mostrando una hoja florifera con un fruto epifilo en desarrollo y los profilos persistentes. C, profilo, cara externa. D, porción del cáliz, cara externa. E, flor longistila: porción del cáliz, cara interna, con pétalos y estambres adnatos (se han cuadriculado las cicatrices dejadas al desprender dos estambres). F, gineceo. (A-F, Prance \& al. 25281). 

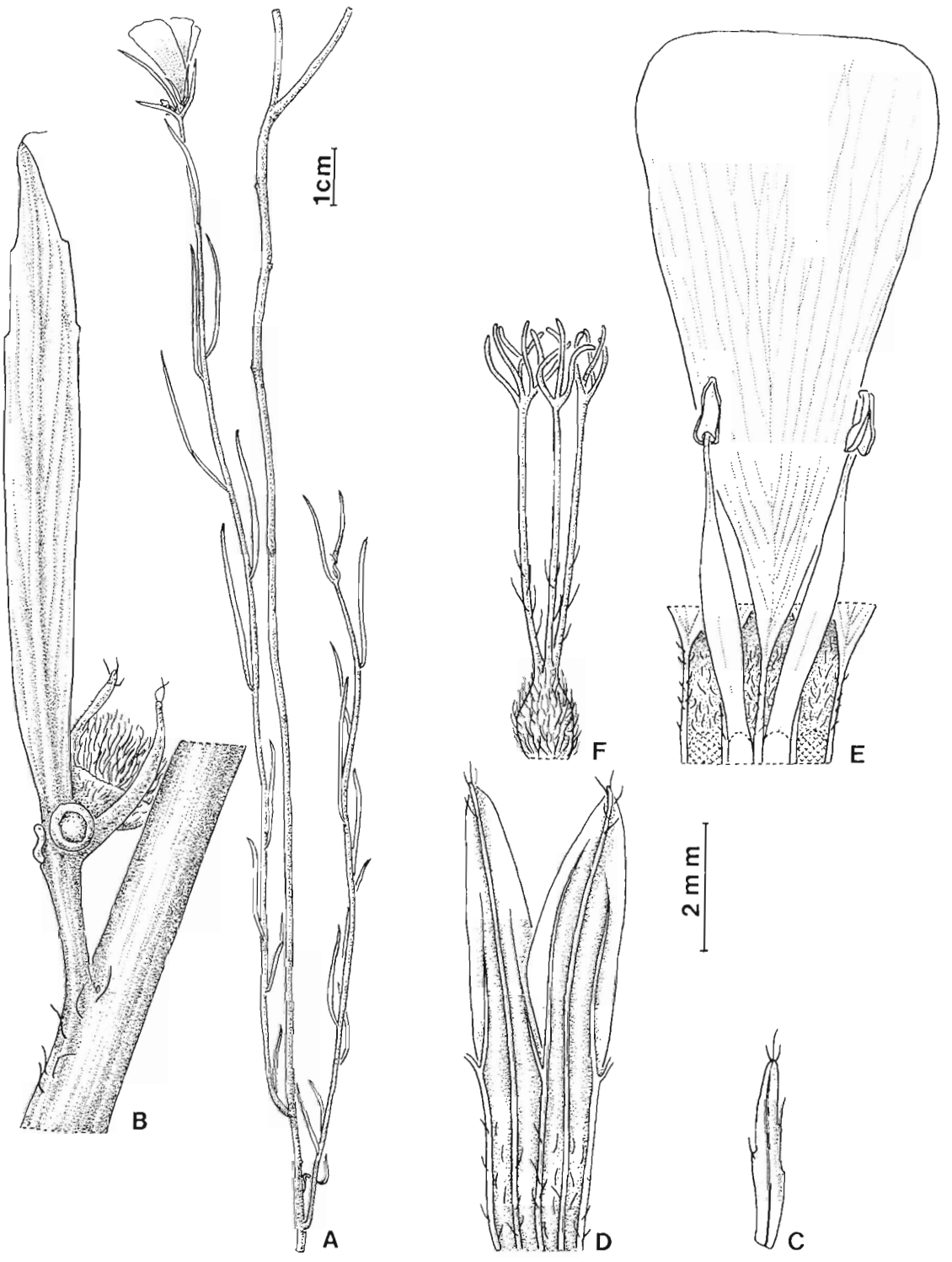
Paratipos: BRASIL. Mato Grosso: Mun. Barra do Garças, lado E da cidade de Barra do Garças, 4.X.1968, Fonseca \& al. 1093 (UB); Cuyabá, 3.XI.1902, Malme s.n. (S), 4.XII.1902, Malme s.n.(S). Rondonia: Vilhena, Campos de Comemoração de Floriano, alem de Campos Novos da Serra do Norte, XI.1911, Hoehne 5539 (CTES, R).

Obs.: En el ejemplar tipo, los estigmas sobrepasan apenas $0,5 \mathrm{~mm}$ a las anteras. En flores longistilas el gineceo es $2 \mathrm{~mm}$ más largo que el androceo; en flores brevistilas el androceo es $2,5 \mathrm{~mm}$ más largo que el gineceo.

Dedico esta especie al Prof. Ghillean T. Prance, quien coleccionó el ejemplar tipo.

$T$. prancei pertenece al grupo de especies graminiformes de Turnera de la serie Leiocarpae; es muy afín a Turnera subnuda Urban, que se distingue por sus hojas muy angostas, uninervias, y a $T$. guianensis Aublet, que se diferencia por tener ovario y cáliz glabros. T. tenuicaulis Urban presenta tallos cilíndricos completamente pilosos y hojas uninervias, y $T$. trigona Urban posee tallos más robustos, de sección angular.

\section{Turnera purpurascens Arbo nov. sp.}

Fig. 7

Herba 0,15-0,30 m altus, folia petiolata, ovata vel elliptica, inferiora interdum subcircularis, supra purpurascens in vivo, utrinque pilosa, nectariis discoideis 0,72,3 mm longis praedita. Flores heterostyli, pedunculo cum petiolo coalito, calyx 10$16 \mathrm{~mm}$ longus, petala flava, ad basin atropurpurea, filamenta cum marginibus nervis petalis adnata. Fructus dorso granulosus. Semina vix curvata, 3,5-4,3 mm longa, tenuiter reticulata, chalaza ampla prominente concava obliqua ad raphem spectante supra basin subconstricta.

Typus. Brasil, Goiás, BR-040, 12 km al N de Luziania, camino a Brasília, 800$1000 \mathrm{~m}$, cerrado destruido, en recuperación, suelo desnudo rojo-arenoso, friable; hojas verde-purpúreas, flores marchitas a la tarde, semillas con arilo muy amplio, 1.11.1990, Arbo M.M., R. Monteiro, A. Schinini \& A. Furlan 3373 (holotipo, HRCB; isotipos, CTES, K, MBM, NY).

Hierba perennizante $15-30 \mathrm{~cm}$ alt, rizoma cilíndrico a veces tortuoso, tallos 1-varios, cilíndricos, erguidos o ascendentes, $1-5$ mm diám., por- 
ción basal con corteza pardo-rojiza, longitudinalmente plicado-estriada, con grietas transversales, luego vestidos con pelos simples, curvado-antrorsos, entremezclados con pelos crespos, hacia los ápices hirsutos. Yemas axilares 1-3 seriales. Ramas seriales no observadas. Hojas coriáceas, patentes o reflexas, en seco a veces plegadas a lo largo de la vena media. Estípulas soldadas a la base del pecíolo, subuladas, 0,6-1,5 mm long., pilosas. Pecíolo semicilíndrico, 2-8 mm long., indumento como el del tallo. Nectarios 1+ I, raramente $2+2$, discoideos, suborbiculares o elípticos, 0,7-2,3 mm long., sésiles, dispuestos en la unión de pecíolo y lámina o desplazados sobre el borde de la lámina, orientados hacia el envés, parte central cubierta por una membrana amarillenta con un poro, reborde 0,2-0,4 $\mathrm{mm}$ lat., rojizo, pilosiúsculo; lámina ovada o elíptica, a veces suborbicular en hojas basales, 12-52 x 6-30 mm, relación largo:ancho $=1,1-2,6: 1$, base anchamente cuneada o redondeada, a veces brevemente atenuada, ápice agudo u obtuso, margen revoluto, a veces plano, piloso, rojizo, aserrado-crenado, aserrado o serrulado, a veces doblemente, excepto en el tercio basal; haz purpurescente en vivo, obscura y rugosa en seco, lisa o maculada, con pelos simples, curvado-antrorsos, adpresos, con base hinchada y coloreada, en hojas basales glabrescente; envés verdoso o castaño claro en seco, a veces con manchitas irregulares purpúreas, glabrescente o con pelos simples esparcidos, y pelos glandulares diminutos, capitados y estipitados; 5-10 pares de venas laterales ligeramente deprimidas en la haz, salientes, rojizas y pilosas en el envés, ángulo de divergencia (30-) 40-50, bifurcándose antes del borde para dar venas que inervan los dientes; venas terciarias recurvas o aproximadamente perpendiculares a la vena media, venación menor inconspicua. Alabastros elipsoides, agudos, rectos, con los mucrones purpúreos del cáliz libres en el ápice. Flores heterostilas (solamente se han visto flores brevistilas). Pedúnculo 1-3 mm long. totalmente adnato al pecíolo; receptáculo plano o ligeramente cóncavo en la parte superior, 1,8 $\mathrm{mm}$ diám. Profilos lineares o angustiobovados, 3,5-7 x 0,5-1,2 mm, enteros, rojizos, pilosos en ambas caras. Cáliz 10-16 mm long., tubo 4-6 mm long., por fuera estrigoso o con pelos simples, largos, curvado-antrorsos entremezclados con otros cortos, por dentro velloso en la garganta, lóbulos angustiovados u ovados, por fuera con indumento como el del tubo, 


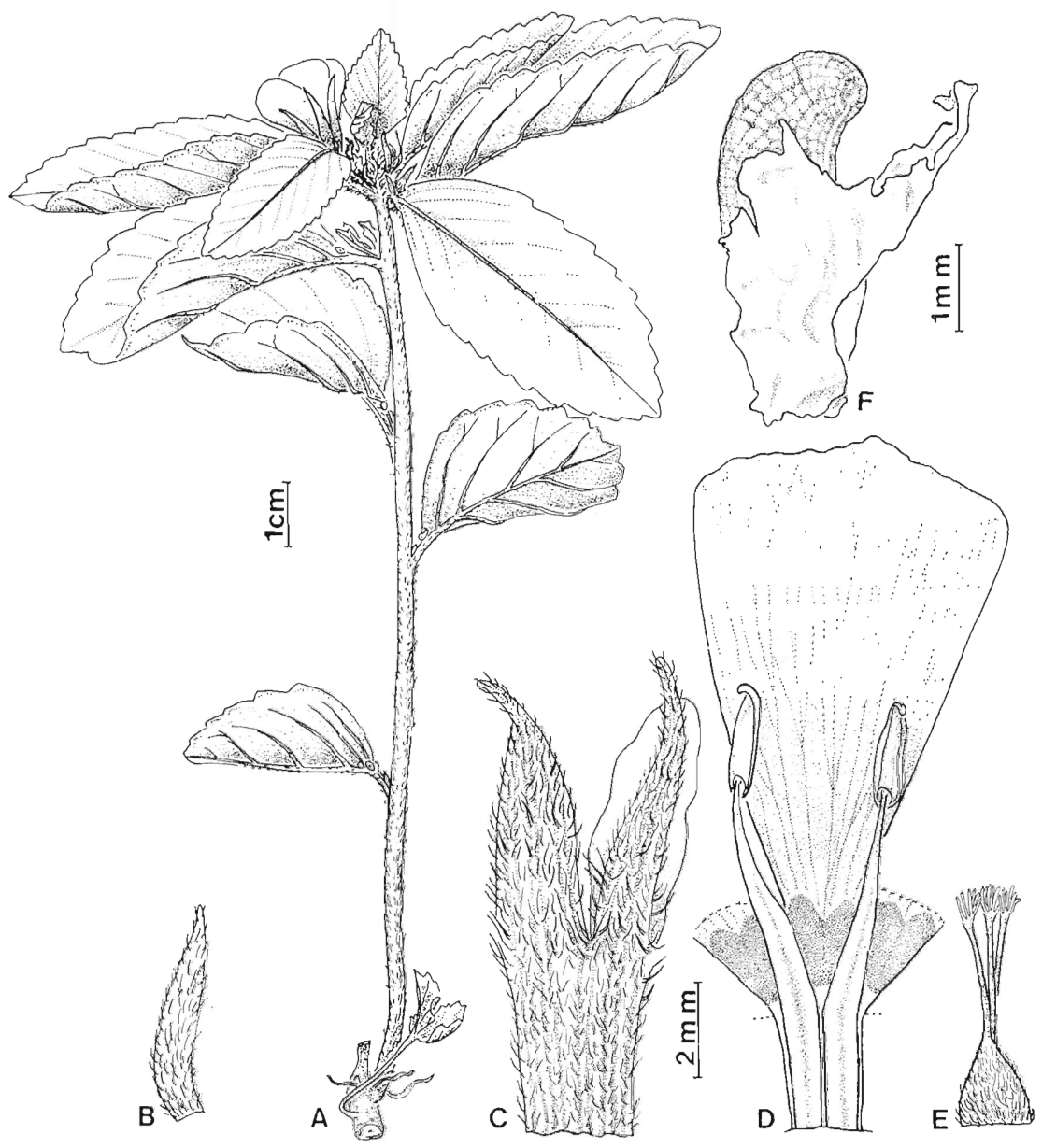

Fig. 7.- Turnera purpurascens. A, planta. B, profilo. C, porción del cáliz, cara externa, mostrando un lóbulo externo y uno interno. D, flor brevistila: porción de la cara interna del tubo calicino mostrando pétalos con mancha basal y estambres adnatos. E, gineceo. F, semilla con arilo, vista lateral-rafeal (A, Alvarenga \& López 562; BE, Irwin \& al. 12458a; F, Arbo \& al. 3373). 
glabros por dentro, bordes internos membranáceos, hialinos, bordes externos rojizos, ápice redondeado, brevemente cuculado, vena media prolongada en un mucrón 1-1,5 mm long. Pétalos amarillos, uña glabra, adnata al tubo del cáliz, lámina obovada, 11-14 x 6-7 mm, cara superior con una mancha purpúrea y en forma de $\mathrm{V}$ en la base, venas coloreadas en la cara externa. Filamentos estaminales complanado-subulados, glabros, 7-8 $\mathrm{mm}$ long. en flores brevistilas, soldados $2,5-3 \mathrm{~mm}$ al tubo floral; anteras angustiovadas, 2,4-3,8 $\times$ 0,5-0,8 mm, base emarginada, ápice agudo recto o ligeramente recurvado en la dehiscencia, filamento inserto en una cavidad basi-dorsal 0,30,4 mm long.; ovario cónico o elipsoide, 1,5-1,8 x 1,2-1,8 mm, densamente piloso, placentas 6-9-ovuladas, estilos cilíndricos, glabros, 2,5-4,2 mm long. en flores brevistilas, estigmas paucirramulosos, 0,3-0,5 $\mathrm{mm}$ long. Fruto suborbicular u ovoide, 6-9 mm diám., receptáculo ca. 2-2,5 mm diám., plano o ligeramente cóncavo, en cuyo borde se observa la cicatriz $0,1-0,2 \mathrm{~mm}$ lat. dejada por el tubo floral al desprenderse; valvas ovadas, ápice agudo u obtuso, cara externa granulosa, estrigosa, cara interna glabra, a veces reticulada o jaspeada. Semilla obovoide, ligeramente curvada, 3,5-4,3 x 1,3$1,5 \mathrm{~mm}$, relación largo:ancho $=2,5-2,6: 1$, negruzca a la madurez, tenuemente reticulada, aréolas transrectangulares ca. $0,15 \times 0,10 \mathrm{~mm}$ o cuadrangulares, exóstoma cónico, amplio, $0,5 \mathrm{~mm}$ long., de base ligeramente estrechada, rafe linear marcada, cálaza prominente, amplia, no o apenas estrechada en la base, ápice oblicuo, cóncavo, orientado hacia la rafe; arilo amplio, envolvente, borde lobulado o lacerado, 4-5 mm long., castaño o amarillento en seco, de células marcadamente papilosas.

Distribución: Especie aparentemente endémica de "campo rupestre" y "cerrado" en Goiás oriental.

Paratipos: BRASIL. Distrito Federal: Fazenda Agua Limpa, UnB., $15^{\circ} 58^{\prime} \mathrm{S} 47^{\circ}$ 54' W, 3.I.1990, Alvarenga \& al. 562 (CTES). Goiás: BR-050, 45-55 km S de Cristalina, ca. $950 \mathrm{~m}$, 30.I.1990, Arbo \& al. 3160 (CTES); Serra dos Cristais, $3 \mathrm{~km} \mathrm{~W}$ of Cristalina, 1175 m, 3.XI.1965, Irwin \& al. 9827 (NY); Chapada dos Veadeiros, $14^{\circ} \mathrm{S}$ $47^{\circ} \mathrm{W}$, ca. $20 \mathrm{~km} \mathrm{~W}$ of Veadeiros, $1000 \mathrm{~m}, 9.11 .1966$, Irwin \& al. 12458a (NY); Serra dos Cristais, ca. $10 \mathrm{~km} \mathrm{~W}$ of Cristalina, $1200 \mathrm{~m}$, 4.III.1966, Irwin \& al. 13458 (NY); Serra Geral do Paraná, ca. 3 km S of Sao João da Aliança, ca. 850 m, 16.III.1971, Irwin \& al. 31909 (NY). 
Obs.: En las flores brevistilas analizadas el androceo es 3-3,5 mm más largo que el gineceo.

Especie perteneciente a la serie Canaligerae. Presenta gran afinidad con T. coriacea Urban, de la Serra do Cipó (Minas Gerais), que se diferencia por sus hojas recurvadas, generalmente obovadas o romboidales, de base atenuada o cuneada y borde aserrado en la mitad apical, y sus pétalos amarillos, raramente con mancha basal brevísima.

\section{Turnera rubrobracteata Arbo nov. sp.}

Fig. 8

Frutex 0,8-1,5 m altus, fo'ia petiolata, lanceolata, 3,4-8,8 cm longa, utrinque pilosa, 2-4 nectariis praedita, $4-8$ venis lateralibus: sub angulo $25-40^{\circ}$ abeuntibus; flores heterostyli in racemum bracteosum collecti, bracteae rubrae, pedunculo cum petiolis bractearum adnato; calyx 9,5-11 mm longus, ca. 2/3 alt. coalito; petala rosea calycem subaequantia; fructus dorso granulosus; semina obovata, obsolete curvata, l,8-2, $1 \mathrm{~mm}$ longa, reticulata, longitrorsum elevatim, transversim modice striata, chalaza prominula concaviuscula.

Typus: Brasil, Espirito Santo, Rio Pancas, Colatina, plantinha rupicola, bracteas vermelhas, petalas levemente arroxeadas, 8.XII.1943, Kuhlmann J.G. 6656 (holotipo, $R B)$.

Arbusto 0,80-1,50 m alt., ramas cilíndricas, longitudinalmente estriadas, corteza pardo-rojiza, lenticelas suborbiculares a elípticas, cicatrices foliares reniformes, con la concavidad hacia arriba, borde inferior saliente. Ramas del año densamente estrigosas a lanosas, con pelos largos, crespos mezclados. Yemas axilares 1-2, ramas seriales desarrolladas. Hojas herbáceas, con 1-3 pares de estípulas a cada lado, subuladas, rojizas, pubescentes, las internas más desarrolladas, 1-2,1 mm long. Pecíolo cilíndrico o semicilíndrico, rojizo, indumento como el de las ramas jóvenes, 2 9 mm long., con 1-2 pares de nectarios en la porción media o apical, orientados lateral o adaxialmente, opuestos o subopuestos, sésiles o ligeramente estipitados, suborbiculares o elípticos, 0,6-1,5 x 0,5-0,9 mm, con un reborde glabro, rojizo, 0,2-0,3 $\mathrm{mm}$ lat., centro cubierto por una membrana rojiza o amarillenta. Lámina lanceolada, 34-88 x 12-27 mm, discolora, base 
cuneada o ligeramente atenuada, ápice agudo, borde aserrado-dentado en la porción apical (44-77\%), ligeramente revoluto, dientes 0,3-0,6 mm long., ápice glanduloso; haz escabrosa, cubierta de pelos cortos, adpresos, de base hinchada, orientados diagonalmente con respecto a la vena media, envés liso, a veces maculado, glabro a densamente cubierto con pelos simples sin orientación definida, 4-8 pares de venas secundarias, alternas o subopuestas, incurvas, ángulo de divergencia $25-40^{\circ}$, ligeramente deprimidas en la haz y prominentes y pilosas en el envés. Racimos bracteados erectos, $2-5 \mathrm{~cm}$ long., terminales o situados en la axila de las hojas apicales. Brácteas rojas o purpúreas, pecíolo cilíndrico, 1,5-4 mm long., indumento como el de las ramas jóvenes, con un par de nectarios orientados lateralmente en la unión con la lámina, o desplazados sobre el margen de la lámina y orientados hacia abajo, a veces ausentes en las brácteas apicales; lámina lanceolada, elíptica, ovada o latiovada, base cuneada, atenuada o a veces redondeada, ápice agudo, margen liso o aserrado en la porción apical, haz escabrosa, con pelos simples cortísimos y otros más largos, adpresos, oblicuos, envés maculado, indumento como en la haz, 1-5 pares de venas incurvas, ligeramente prominentes, alternas y opuestas. Flores heterostilas. Pedúnculo floral 3,5-6 mm long., soldado al pecíolo y a veces a la porción basal de la vena media, a veces una porción apical libre de 0,5-1,5 $\mathrm{mm}$ long. Pedicelo nulo. Receptáculo dilatado y aplanado. Profilos lineares, dispuestos en la base del tubo floral, rojizos, 4-10 x 0,3-1,5 mm, estrigosos, estipulados, estípulas 0,6-0,9 mm long. Cáliz 9,5-11 mm long., soldado en ca. 2/3 de su longitud, tubo ligeramente dilatado en la porción basal; cara externa con pelos simples cortos, erectos, y a veces pelos largos antrorsos especialmente sobre las venas prominentes; cara interna glabra en la porción basal, vellosa en el tercio superior; lóbulos triangulares, trinervados, cara externa con pelos largos antrorsos, cara interna glabra excepto en la garganta, mucrón apical 0,1-0,3 mm long. Corola rosada, igual que el cáliz o ligeramente menor o mayor; uña pilosa, adnata al tubo del cáliz, lámina obovada, 3-3,5 x 1-1,9 mm, totalmente glabra o vellosa en la base, margen levemente eroso en el ápice. Filamentos estaminales complanadosuhulados hrevemente soldadns al tubo floral en la base. soldados entre 
sí por sus bordes 0,3-2 mm long., vellosos en los 2/3 apicales, 5-6 mm long. en flores longistilas, $7-8 \mathrm{~mm}$ long. en flores brevistilas; anteras triangulares o angustiovadas, 1,3-1,7 $\times 0,4-0,6 \mathrm{~mm}$, rectas o ligeramente curvas después de la dehiscencia, filamento inserto en una cavidad basi-dorsal 0,20,6 mm long., apículo 0-0,3 mm long. Ovario elipsoidal o cónico, 1,5-2,5 x 1,1-2 mm, estrigoso a densamente cubierto de pelos simples, gruesos, adpresos, antrosos; estilos filiformes, en flores longistilas 5,5 mm long., villosos en la porción basal, en flores brevistilas 2,5-3 mm long., hirsutos excepto en el ápice; estigma penicilado, amarillento, 0,4-1 mm long. Cápsula cubierta por los restos florales persistentes, $4 \mathrm{~mm}$ diám., valvas latiovadas, cara externa granulosa, estrigosa especialmente en el ápice, cara interna glabra, lisa. Semilla obovoide, $1,8-2,1 \times 1,2-1,3 \mathrm{~mm}$, recta o ligeramente curvada, parda, glabra, reticulada, estrías longitudinales bien marcadas, muros transversales más tenues, aréolas transrectangulares, con una depresión punctiforme en el centro, exóstoma cónico, rafe linear apenas marcada, cálaza saliente, deprimida en el centro; arilo membranáceo, unilateral, 1-1,5 mm long., células lisas.

Distribución: Se han coleccionado hasta el momento unos pocos ejemplares en el estado de Espirito Santo. Es una planta propia de asociaciones rupestres.

Paratipos: BRASIL. Espirito Santo: Serra da Cima, -de Nova Venecia, 16.XI.1953, Duarte 4001 (RB); Pedra do Feijoal, Rio Doce. 7.IX.1951, Kuhlmann s.n. (RB 102192); margens do Rio Doce, Pedra do Feijoal, 28.IV.1946, Kuhlmann 309 (CTES).

Fig. 8.- Turnera rubrobracteata. A, rama florífera. B, profilo. C, porción de la cara externa del cáliz, mostrando un lóbulo interno y uno externo. D, flor brevistila: cara interna del tubo calicino, mostrando los pétalos y cuatro estambres adnatos, soldados entre sí a distintas alturas; se ha cuadriculado la cicatriz dejada al desprender un estambre. E, gineceo. F, semilla con arilo, vista lateral (A, Kuhlmann s.n., RB 102192; B-E, Kuhlmann 309; F, Kuhlmann 6656). 

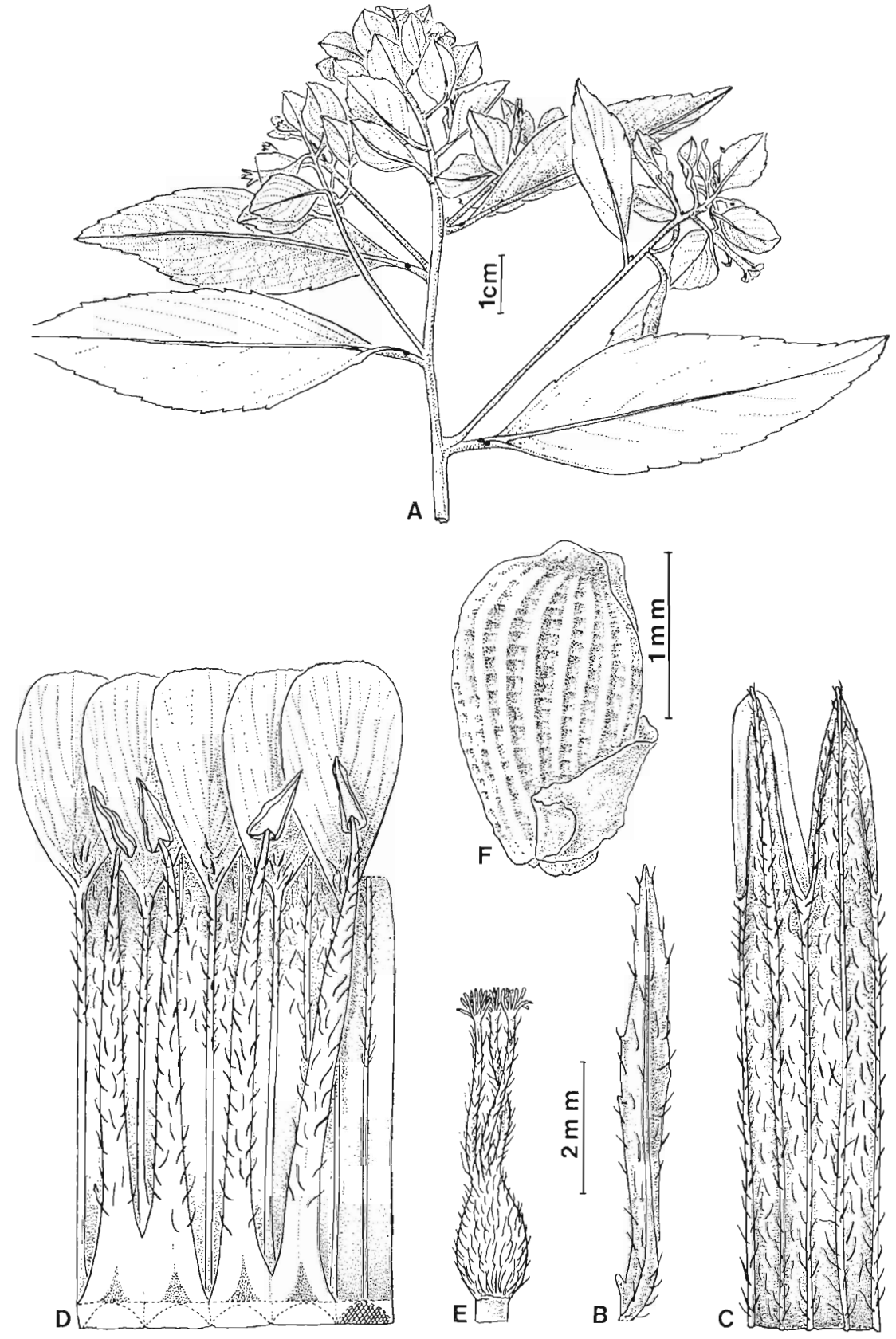
Obs.: Las flores brevistilas analizadas presentan el ovario muy reducido y el androceo 1,5-3,5 mm más largo que el gineceo. En la flor longistila observada la diferencia en longitud gineceo-androceo es de 1,5 mm.

Sus afinidades son inciertas, presenta rasgos en común con especies de series diferentes. La inserción de los filamentos estaminales recuerda a las especies de la serie Annulares, pero su cohesión es igual a la que se presenta en T. annectens Arbo (Arbo, 1990), de la serie Stenodictyae Urban. Presenta pedúnculo floral desarrollado, adnato al pecíolo como las especies de las series Leiocarpae y Canaligerae. Los restos florales son persistentes, y recubren el fruto, como en las especies de las series Anomalae y Microphyllae Urban. Sus semillas recuerdan las de algunas especies de la serie Capitatae.

Es una especie muy llamativa, que ya Kuhlmann reconoció como nueva, destacando el color de las brácteas en el nombre que le dió en sus etiquetas de herbario.

\section{Turnera urbanii Arbo nov. sp.}

Fig. 9

Turnera eichleriana Urban ex Glaziou, Bull. Soc. Bot. France 52, mém. 3: 312, 1909. Nomen nudum.

Fruticulus, ramis vetustioribus plicato-striatis, ramis hornotinis tomentosovelutinis. Folia elliptica, elliptico-lanceolata vel obovata, petiolus $2-4$, nectariis amplis marginibus pilosis instructus. Flores homostyli; pedunculi liberi 3,5-8 mm longi; pedicelli nulli; prophylla subulata, 0,5-2 mm basi calycem distantes; calyx 8$11 \mathrm{~mm}$ longus; corolla carnea, intus glabra; filamenta basi tubo 0,5-0,7 mm adnata, utrinque ad medium pilosa. Semina obovata, 2,7-3 mm longa, obsolete curvata, longitrorsum elevatim, transversim obsolete densissimeque striata, epidermis papillosa.

Typus. Brasil, Pará, Rio Capim, ad lai. Putirytá, 21.II.1882, Schwacke III I65 (holotipo, GOET).

Subarbusto, ramas pardas, cilíndricas, levemente estriadas, algo lustrosas, glabrescentes, pelos simples, crespos, entremezclados con otros más largos, curvados, antrorsos, entrenudos 7-28 mm long., ramas del año rojizas, 
tomentosas a velutinas, indumento blanco-amarillento, yemas seriales 2-3, ramas seriales floríferas desarrolladas. Hojas cartáceas, discoloras. Estípulas triangular-subuladas, 1-1,5 mm long., rojizas, pilosas. Pecíolo cilíndrico, 4,5$8,5 \mathrm{~mm}$ long., a veces ligeramente surcado en la haz, densamente amarillentopubescente. Nectarios 1-2 pares, circulares o elípticos, 0,7-1 mm diám., con reborde obscuro, piloso, centro pardo-amarillento, ubicados lateralmente en el ápice del pecíolo. Lámina elíptica, elíptico-lanceolada o largamente obovada, $25-90 \times 7-25 \mathrm{~mm}$, base cuneada o atenuada, margen entero en el tercio basal, luego aserrado-crenado, dientes de lados desiguales, el apical más corto, a veces con nectarios circulares diminutos en las escotaduras sobre el envés, ápice agudo o acuminado; haz pardo-rojiza en seco, algo lustrosa, a veces maculada, con líneas irregulares, laberínticas, amarillentas, contrastando con el fondo pardo-rojizo, con algunos pelos simples y adpresos especialmente sobre las venas, envés oliváceo en seco, piloso; venas ligeramente deprimidas en la haz, prominentes en el envés, 6-7 pares de venas secundarias alternas o subopuestas, ángulo de divergencia $35-45^{\circ}$, incurvas, terminando en arcos que se unen con las superadyacentes, venas terciarias ligeramente curvadas, dispuestas casi en ángulo recto con respecto a la vena media, venación menor inconspicua. Flores axilares, homostilas, solitarias, o dispuestas en ramitas seriales floríferas con hojas reducidas, bracteiformes, 10-16 x 2,5-4 mm. Alabastros rectos, con los mucrones libres en el ápice. Pedúnculo libre, cilíndrico, 3,5-8 mm long., densamente piloso. Pedicelo nulo. Profilos dos, opuestos o subalternos, dispuestos a 0,5-2 $\mathrm{mm}$ de la base del cáliz, subulados, 1,7-3 x 0,1-0,5 mm, pilosos, margen subentero, con 1-2 lacinias subuladas a cada lado en la base. Cáliz $8-11 \mathrm{~mm}$, soldado en ca. 1/ 3 de su longitud, tubo campanulado, piloso por fuera especialmente en las venas, glabro por dentro, frecuentemente con 3-5 apéndices pistiliformes en la garganta; lóbulos triangular-ovados, 3-5-nervados, pilosos por fuera y glabros por dentro, mucrón 0,5-0,7 mm long. Corola cárnea, 0,5-2 mm más larga que el cáliz, pétalos con la uña glabra, lámina obovada, 7-9 x 2,5-3 $\mathrm{mm}$, base atenuada, pilosa en la haz, ápice brevemente acuminado. Filamentos estaminales complanado-subulados, 6-6,5 mm long., pubérulos en ambas caras en la porción central, soldados 0,5-0,7 $\mathrm{mm}$ al tubo floral en la base; 

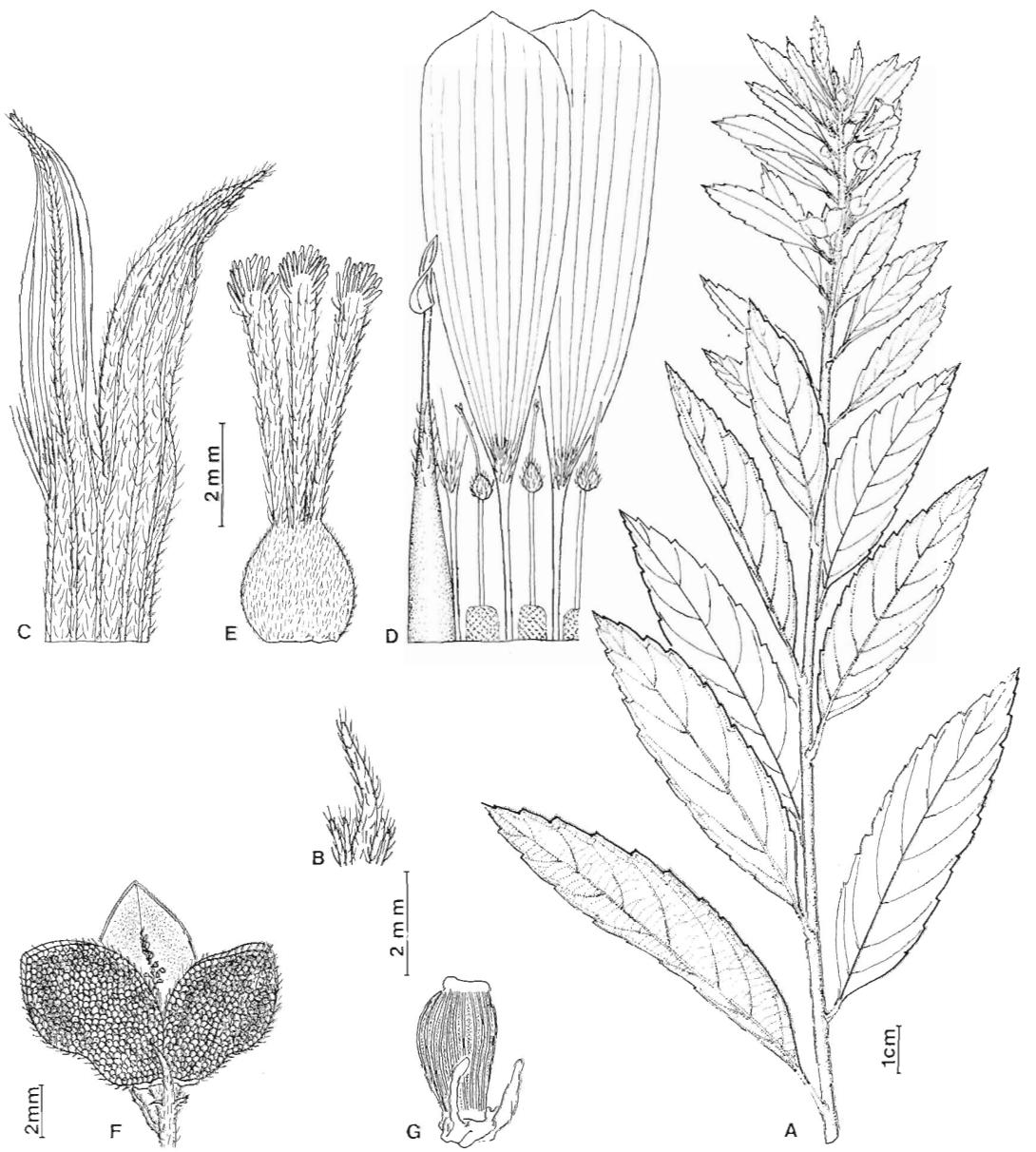

Fig. 9- Turnera urbanii. A, rama florífera. B, profilo. C, porción de la cara externa del cáliz, mostrando un lóbulo externo y uno interno. D, porción de la cara interna del tubo calicino, con pétalos y estambres adnatos, mostrando los apéndices pistiliformes en la garganta; se han cuadriculado las cicatrices dejadas al desprender los estambres. E, gineceo. F, fruto. G, semilla con arilo, vista lateral (Schwacke III $165)$. 
anteras dorsifijas, 1,2-1,5 x 0,5-0,7 mm, base emarginada, no apiculadas, rectas o ligeramente curvadas después de la dehiscencia. Ovario ovoide o globoso, 2-2,5 x 1,7-2 mm, densamente tomentoso, placentas ca. 15ovuladas; estilos cilíndricos, hirsutos, 4-5 mm long.; estigmas penicilados, amarillentos, 0,7-1 $\mathrm{mm}$ long. Fruto globoso, 6-8 $\mathrm{mm}$ diám., valvas ovadooblongas, cara externa parda, tuberculada, pilosa, cara interna glabra, lisa, algo lustrosa, amarillenta o jaspeada. Semilla obpiriforme, ligeramente curvada, parda, 2,7-3 x 1,5-1,7 mm, longitudinalmente estriada, las depresiones con estrías transversales apenas visibles, epidermis papilosa, exóstoma cónico poco prominente, rafe linear apenas marcada, cálaza saliente y deprimida en el centro; arilo membranáceo, rasgado, células lisas, llegando hasta la mitad de la semilla.

Distribución: Se conocen sólo dos ejemplares del estado de Pará. La localidad de Glaziou es probablemente falsa, su ejemplar puede ser un duplicado de Schwacke III 165 (Wurdack, 1970).

Paratipos: BRASIL. Minas Gerais: Serra de Caraça, 18.X.1882, Glaziou 13915a (P). Pará: Rio Capim, 26.III.1949, Fróes \& al. 24150 (UB).

Obs.: Las flores del ejemplar tipo y las de Glaziou 13915 presentan apéndices pistiliformes en la garganta. Estos apéndices tienen un abultamiento en la base, semejando un ovario, una extensión filiforme que parece un estilo, rematado en una porción dilatada que aparenta un estigma. La única flor observada en el espécimen Fróes \& al. 24150 no presenta dichos apéndices.

En Turnera lamiifolia Urban y algunas especies de Piriqueta se han observado apéndices estiliformes en las flores, ubicados en la misma posición que los de T. urbanii.

Especie perteneciente a la serie Stenodictyae Urban, afín a Turnera macrophylla Urban, que se diferencia por sus hojas más grandes, hasta 16 mm long., sus profilos dispuestos en la base del cáliz, y sus flores heterostilas (longistilas, brevistilas y mediostilas). 


\section{Turnera arenaria (Urban) Arbo nov. comb.}

Turnera melochioides St. Hil., Juss. \& Cambess. var. arenaria Urban, Jahrb. Königl. Bot. Gart. Berlin 2: 115, 1883. Turnera arenaria Spruce ex Urban prosyn. Typus. Brasil. Pará: in vicinibus Santarem, XI.1849-III.1850, Spruce s.n. [seg. Urban 743] (lectotipo, aquí designado, P!; isotipos!, FI, P, W).

Turnera melochioides St. Hil., Juss. \& Cambess. var. angustifolia Urban, Jahrb. Königl. Bot. Gart. Berlin 2: 116, 1883. Typus. Brasil. Piauí: Gardner 2171 (lectotipo, aquí designado, P!).

Turnera melochioides St. Hil., juss. \& Cambess. var. oblongifolia Urban, Jahrb. Königl. Bot. Gart. Berlin 2: 116, 1883. Typus. Brasil. Alagoas, Gardner 1247 (lectotipo, aquí designado, P!; isotipos!, FI, NY, P, S, W).

Especie perteneciente a la serie Leiocarpae Urban. Es afín a $T$. melochioides St. Hil., Juss. \& Cambess., y T. curassavica Urban, con las que comparte la posesión de hojas floríferas apicales bracteiformes, con nectarios notables, reunidas en racimos umbeliformes apicales o axilares. Se diferencia de la primera por sus hojas más angostas, raramente discoloras, y sus semillas más cortas, 1,5-1,9 mm long. De la segunda se distingue fácilmente por presentar el tubo calicino completamente piloso.

\section{Reconocimientos}

Agradezco a los curadores de los herbarios BM, BR, C, CAS,CEN, CEPEC, DS, F, FI, G, GH, GOET, HRCB, K, LIL, M, MBM, MEXU, MICH, MO, NY, P, R, RB, S, SP, SPF, UB, US y W el préstamo del material estudiado; a Bruno Manara y a Carlos Zanín la revisión de las diagnosis latinas. Los viajes de colección a Brasil fueron subsidiados por la National Geographic Society (Grant N 4175/89), agradezco a los colegas de la Universidade de São Paulo (SPF) y Universidade Estadual de São Paulo (HRCB) y a Aurelio Schinini su participación y colaboración en los mismos. Las figuras 1, 2, 5, 6, 7 y 8 fueron preparadas por Liliana Gómez, la 3 y la 4 por Ricardo Vispo y la 9 por Víctor Maruñak; los detalles florales se hicieron sobre dibujos a lápiz de la autora. 


\section{Bibliografía}

Arbo, M.M. 1981. Novedades en Turneráceas de Brasil. Bonplandia 5: 111-122.

- 1985. Notas taxonómicas sobre Turneráceas americanas. Candollea 40: $175-191$.

- 1986. Paraguay, centro importante de especiación en las Turneráceas. Candollea 41: 211-218.

- 1990. Turneraceae: Novedades para la Guayana Venezolana. Ann. Missouri Bot. Gard. 77: 340-352.

- \& A. Fernández. 1987. Cruzamientos intra e interespecíficos en Turnera serie Canaligerae. Bonplandia 6 (1): 23-38.

Fernández, A. 1987. Estudios cromosómicos en Turnera y Piriqueta (Turneraceae). Bonplandia 6 (1): 1-21.

Joly, A. B. 1970. Conheça a vegetação brasileira. 181 págs. Ed. Universidade de São Paulo.

Solís Neffa V.G. \& A. Fernández. 1993. Estudios cromosómicos en especies de Turnera (Turneraceae). Bonplandia 7 (1-4): 101-118.

Urban, I. 1883. Monographie der familie der Turneraceen. Jahrb. Königl. Bot. Gart. Berlin 2: 1-155.

- 1914. Turneraceae novae II. Repert. Spec. Nov. Regni Veg. 13: 152-158.

Wurdack, J.J. 1970. Erroneous data in Glaziou collections of Melastomataceae. Taxon 19 (6): 911-913. 